\title{
Cognitive Mechanisms of Treatment in Depression
}

\author{
Jonathan P Roiser ${ }^{\star,}$, Rebecca Elliott ${ }^{2}$ and Barbara J Sahakian ${ }^{3}$ \\ ${ }^{1}$ UCL Institute of Cognitive Neuroscience, London, UK; ${ }^{2}$ Neuroscience and Psychiatry Unit and Academic Health Sciences \\ Centre, University of Manchester, Manchester, UK; ${ }^{3}$ University of Cambridge Department of Psychiatry and MRC/Wellcome \\ Trust Behavioural and Clinical Neuroscience Institute, Addenbrookes Hospital, Cambridge, UK
}

\begin{abstract}
Cognitive abnormalities are a core feature of depression, and biases toward negatively toned emotional information are common, but are they a cause or a consequence of depressive symptoms? Here, we propose a 'cognitive neuropsychological' model of depression, suggesting that negative information processing biases have a central causal role in the development of symptoms of depression, and that treatments exert their beneficial effects by abolishing these biases. We review the evidence pertaining to this model: briefly with respect to currently depressed patients, and in more detail with respect to individuals at risk for depression and the effects of antidepressant treatments. As well as being present in currently depressed individuals, negative biases are detectable in those vulnerable for depression due to neuroticism, genetic risk, or previous depressive illness. Recent evidence provides strong support for the notion that both antidepressant drugs and psychological therapies modify negative biases, providing a common mechanism for understanding treatments for depression. Intriguingly, it may even be possible to predict which patients will benefit most from which treatments on the basis of neural responses to negative stimuli. However, further research is required to ascertain whether negative processing biases will be useful in predicting, detecting, and treating depression, and hence in preventing a chronic, relapsing course of illness. Neuropsychopharmacology Reviews (2012) 37, 117-136; doi: I0.1038/npp.201 I. 183; published online 5 October 201 I
\end{abstract}

Keywords: depression; cognition; neuroimaging; treatment; antidepressants; psychological therapy

\section{INTRODUCTION}

Neuropsychiatric disorders place a heavy burden on sufferers, their carers, and society. For example, depression is a common, debilitating, and life-threatening illness, projected to become the second leading cause of disability by 2020 by the World Health Organization. Therefore, the development of more efficacious treatment strategies remains a priority. Traditionally, treatment strategies for depression have been divided into 'monoamine medication' approaches, such as selective serotonin reuptake inhibitors (SSRIs) or selective noradrenaline reuptake inhibitors (SNRIs), and 'psychological therapy' approaches, such as cognitive behavioral therapy (CBT). The former approach is motivated by the monoamine hypothesis of depression (Asberg et al, 1976; Schildkraut, 1965), which holds that a neurochemical imbalance directly causes the core depressive symptoms of dysphoria (low mood) and anhedonia (loss of ability to experience interest or pleasure). The latter

${ }^{\star}$ Correspondence: Dr JP Roiser, Institute of Cognitive Neuroscience, University College London, 17 Queen Square, London, WC1N 3AR, UK, Tel: + 44207679 1170, Fax: + 44207813 2835, E-mail: j.roiser@ucl.ac.uk Received 2 June 2011; revised 4 August 2011; accepted 4 August 2011 approach conceptualizes depression as a state in which selfreinforcing dysfunctional negative schemata - fixed internal models of the self, the world, and the future that are instantiated by early adverse experiences - come to dominate every aspect of an individual's information processing (Beck, 1967, 1976).

More recently, several reviews have converged on a cognitive neuropsychological model of depression, which attempts to reconcile these approaches (Clark et al, 2009; Harmer et al, 2009a; Robinson and Sahakian, 2008; Sahakian and Morein-Zamir, 2011). The central tenet of this model suggests a causal role for negative affective biases in the development, maintenance, and treatment of depression. Here, we extend this model, in particular emphasizing the potential importance of affective cognitive control in promoting resilience to depression (Figure 1), and review the evidence pertaining to it. As recent reviews have presented evidence supporting the presence of negative affective biases in depressed patients in some detail (Clark et al, 2009; Harmer et al, 2009a; Robinson and Sahakian, 2008; Sahakian and Morien-Zamir, 2011), we only provide a brief overview of these findings. We consider in greater depth the evidence that individuals at risk for 
depression exhibit negative affective biases, and that pharmacological treatments for depression affect such biases directly, predictions made explicitly by the cognitive neuropsychological model. At the end of this paper, we also consider the clinical implications of this model, specifically whether differential response to pharmacological $v s$ psychological therapy on an individual level might be predicted by negative affective processing before treatment (Figure 2 ).

\section{Treatments for Depression}

Both the psychological and the monoamine models have yielded efficacious treatment strategies for depression, as supported by numerous systematic reviews (Fournier et al, 2010; Hollon et al, 2006), although it has been questioned whether the effects of some pharmacological treatments differ reliably from those of placebo, at least in mild-tomoderate cases of depression (Fournier et al, 2010). Indeed, available evidence suggests that a combination of the two approaches may provide the best long-term outcome (National Institute for Clinical Excellence, 2009; Simon et al, 2006). However, neither treatment approach works in every individual and a substantial minority of patients respond to neither, going on to experience chronic symptoms (Simon et al, 2006). It is also not possible to reliably predict on the basis of symptomatic profile whether an individual patient will respond better to one treatment approach or to the other. Unfortunately, in the past 20 years, no improved treatment options based on either these approaches (ie, medications targeting the monoamine systems or psychological therapies that work substantially better than those already available) have been developed for depression. The best monoamine medications remain ineffective in approximately $30-40 \%$ of patients in the short term (Trivedi et al, 2006), and despite the relatively superior long-term efficacy of psychological therapies, $\sim 30 \%$ of patients will relapse within 12 months after treatment (Hollon et al, 2006).

Various approaches to psychological therapy exist, although it is beyond the scope of this review to examine them all here. However, it should be noted that the different therapies discussed in this review are based on quite different assumptions regarding the etiology of depressive symptoms. CBT (or simply cognitive therapy: CT) is focused on modifying negative cognitions (dysfunctional schemata) that are held to be the primary cause of depression (Beck, 1976). BA (behavioral activation) therapy, by contrast, adopts a more radical behaviorist approach, ignoring internal cognitions. It works on the assumption that avoidance (driven by negative reinforcement) is the central cause of depression, and seeks to re-engage patients in positively reinforcing activities (Dimidjian et al, 2011). Well-controlled trials have suggested equivalence between BA and CBT (Jacobson et al, 1996; Dimidjian et al, 2006). Cognitive bias modification (CBM) is a more experimental psychological treatment and most closely aligned with the model outlined in this review; whether this approach is as efficacious as more traditional psychological treatments remains to be established (Hallion and Ruscio, in press). CBM assumes that negative affective biases are the central cause of depression, and attempts to train individuals to process positive information preferentially (MacLeod et al, 2002; Matthews and MacLeod, 2002).

The most recent innovative treatment options for depression have emerged from different models of the etiology of depressive illness. These are less well tested than monoamine medications and psychological therapies, and include fast-acting medications targeting the glutamate system, especially the NMDA receptor, directly (ketamine: Zarate et al, 2006) and indirectly through the cholinergic system (scopolamine: Furey and Drevets, 2006), repeated transcranial magnetic stimulation (rTMS) in the dorsal part of the prefrontal cortex (Fregni et al, 2006), and deep brain stimulation (DBS), particularly in the subgenual anterior cingulate cortex (ACC) region of the prefrontal cortex (Mayberg et al, 2005). In particular, the latter two methods have arisen from an appreciation of cognitive neuroscience findings in individuals with and without depression, ie, the neural circuits subserving mood and emotion processing in healthy volunteers (Phillips et al, 2003a), which seem to operate abnormally in depression (Mayberg et al, 1999; Phillips et al, 2003b).

\section{The Cognitive Neuropsychological Model of Depression}

At first glance, the ability of such a wide-ranging spectrum of options to treat depression, ranging from psychological therapies, through various pharmacological interventions, to invasive and non-invasive brain stimulation, is puzzling. What do these therapeutic approaches have in common? An increasingly influential explanatory framework suggests that distorted information processing, specifically relating to reward and emotional processing biases (which in this article we term 'affective processing'), may represent an important pathway through which these disparate treatments exert their beneficial effects (Clark et al, 2009; Harmer et al, 2009a; Robinson and Sahakian, 2008). Broadly, this cognitive neuropsychological approach conceptualizes core depressive symptoms, such as dysphoria and anhedonia, as learned states engendered by dysfunctional negative schemata, instantiated over long periods by affective information processing biases (Pringle et al, 2010).

In some ways, this notion is similar to longstanding psychological models of depressive symptoms that first stimulated the development of psychological therapies such as CBT (Beck, 1967, 1976). These earlier psychological models focused on the importance of early adverse life experiences, which were proposed to lead to cognitive distortions, errors such as overgeneralization and arbitrary inference, and ultimately negative schemata (Beck, 1976). In these models, the negative schemata ultimately cause biased information processing, and CBT highlights the importance of challenging internally generated negative automatic 


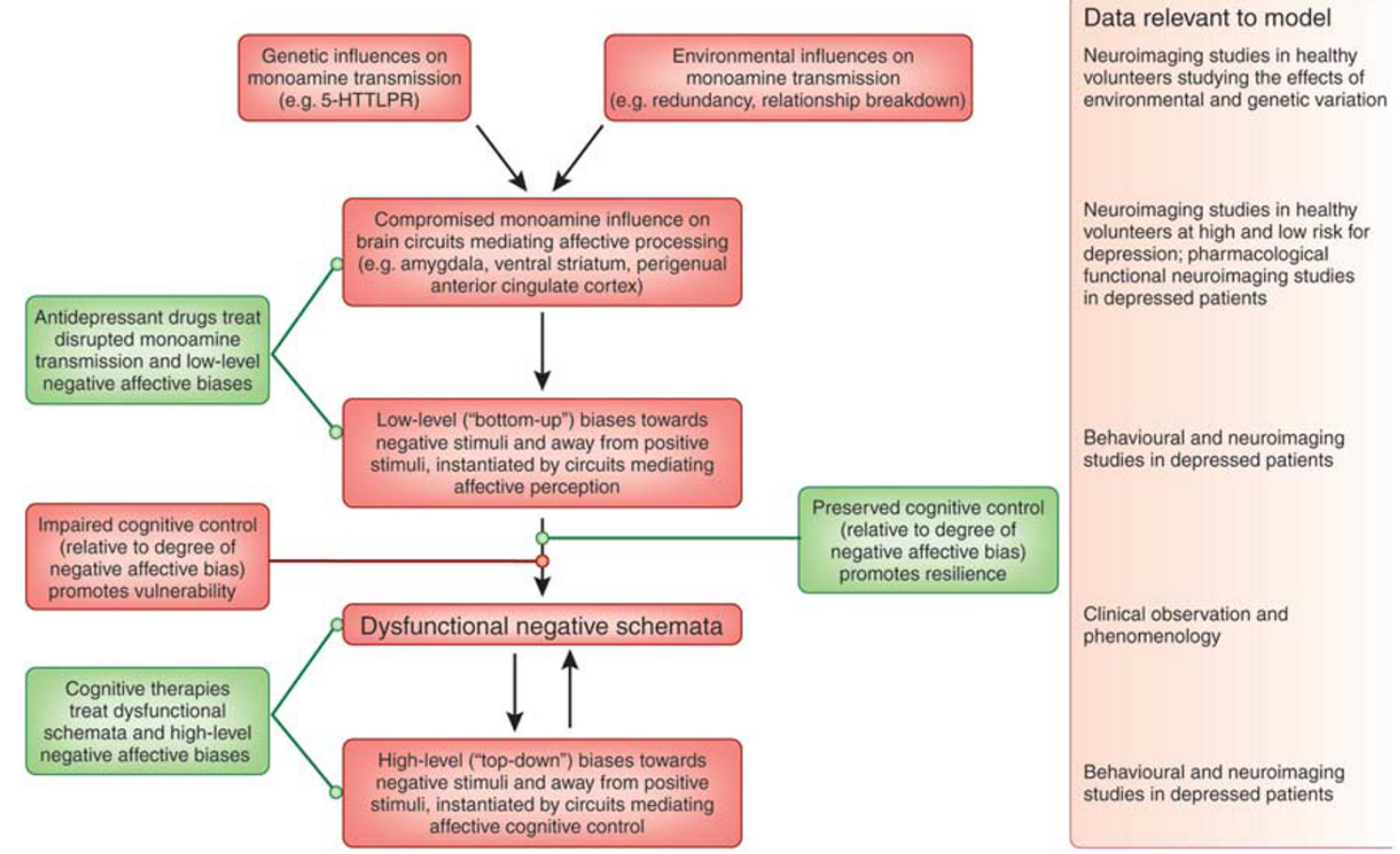

Figure 1. The extended cognitive neuropsychological model of depression. Red boxes indicate factors contributing to the development and maintenance of depressive symptoms. Green boxes indicate factors contributing to the treatment of and recovery from depression. 5-HTTLPR: serotonin transporter-linked polymorphic region.

thoughts, helping to break down schemata. In contrast to earlier psychological models, the cognitive neuropsychological approach suggests that the negative schemata are not the direct result of adverse early experiences, but instead are instantiated by negative affective processing biases. These biases are posited to be caused by alterations in monoamine transmission, which might themselves be related to either environmental or genetic factors, or more likely a combination of both (Figure 1). Although at first glance this distinction may appear subtle, its implications are substantial. In particular, the cognitive neuropsychological approach emphasizes a fundamental role for negative affective biases in the etiology and treatment of depression; moreover, it offers a framework in which the traditional 'psychological' and 'neurochemical' explanations of depression might be reconciled.

As reviewed briefly below and more extensively elsewhere (Clark et al, 2009; Gotlib and Joormann, 2010), negative affective biases have been reported to co-occur with depressive symptoms across a range of cognitive domains. Over time, such consistently biased input may shift the default automatic processing of affective information more negatively, creating stable dysfunctional self-reinforcing negative schemata, which ultimately themselves come to influence affective processing. These schemata are stable and self-reinforcing because, in addition to the 'bottom-up' negative biases that contributed to their formation (eg, perceptual biases), they may themselves instantiate 'topdown' negative biases that help to maintain the depressive state (eg, attentional biases) (see Figure 1). A broader neuropsychological framework, although still perhaps oversimplistic, could incorporate not only just affective perception but also affective cognitive control (ie, the ability to regulate negative emotional experience, to challenge the negative automatic thoughts arising from the negative schemata, and to disregard external negative stimuli: Gotlib and Joorman, 2010), and also affective learning (ie, processes that create, maintain, or modify the negative schemata).

Contrary to traditional models of antidepressant drug action (Schildkraut, 1965), this framework suggests that pharmacological interventions do not affect mood directly. Instead, antidepressant drugs are proposed to alter the brain's processing of affective stimuli (Clark et al, 2009; Harmer et al, 2009a; Robinson and Sahakian, 2008), allowing the learned states of dysphoria and anhedonia to remit gradually as the 'bottom-up' biases contributing to them are attenuated or abolished. Importantly, this model predicts that antidepressant drugs should positively bias emotional information in those without a history of affective disorders and in currently depressed individuals (Harmer et al, 2009a). This idea echoes a prominent and complementary model of psychosis, the 'aberrant salience' hypothesis, in which antipsychotic drugs are proposed to exert their beneficial effects by dampening down the brain's processing of stimuli that are inappropriately assigned importance or relevance, allowing delusions to remit gradually (Kapur, 2003). Such a gradual change is consistent with findings that, although monoamine medications typically exert their effects at the synapse within hours, recovery from depression typically takes at least several weeks. 
In the cognitive neuropsychological model, the effects of psychological therapies such as CBT are quite different to those of antidepressant medications. Instead of acting on information processing biases directly, $\mathrm{CBT}$ is proposed to contribute to the gradual breakdown of the dysfunctional schemata that maintain the learned states of dysphoria and anhedonia in a 'top-down' manner, by training affective cognitive control (in other words, teaching patients to disengage from negative external stimuli and internal representations) and stimulating re-learning. As these schemata may themselves also contribute to affective information processing biases, psychological therapies may resolve high-level (eg, attentional) negative biases, although their effect on low-level (eg, perceptual) negative biases would be predicted to be relatively minor.

Finally, and more speculatively, in this framework, novel treatment approaches for depression could be conceptualized as making the negative schemata more plastic and temporarily amenable to change (drugs altering NMDA receptor function directly such as ketamine or indirectly such as scopolamine), increasing affective cognitive control (rTMS in the dorsal prefrontal cortex), or directly modulating neural circuits participating in affective perception and regulation (DBS in the subgenual ACC).

\section{Predictions of the Cognitive Neuropsychological Model}

This model of the etiology and treatment of depressive symptoms, inspired by cognitive neuroscience and focusing on distorted affective processing, has a number of attractive features. It is consistent with some of the core diagnostic criteria for depression that are most obviously cognitive in nature, such as anhedonia and difficulty in decision making. It provides a single framework for the mechanisms of a disparate spectrum of efficacious interventions, and helps to explain the different timescales over which they work. It helps to understand why some comorbidities among psychiatric disorders are so common: eg, the co-occurrence of depressive symptoms with psychotic symptoms that occurs in both schizoaffective disorder and affective psychosis; both of these could potentially be explained in terms of compromised affective cognitive control. The framework is also consistent with findings of pleiotropy, one genetic variant conferring risk for a number of different disorders, a pattern increasingly emerging from genome-wide association studies (Huang et al, 2010; Purcell et al, 2009). Finally, although broad in scope, this framework makes some clear testable predictions, which form the focus for the rest of this review:

(1) Dysfunctional affective cognitive processes should be detectable reliably in currently depressed patients, in various different cognitive domains (such as perception, attention, learning and memory, and cognitive control);

(2) As dysfunctional affective cognitive processes are proposed to drive the development of the negative schemata that cause core depressive symptoms, they should be detectable in individuals at risk for depression before the onset of frank illness, although they may not completely disappear after remission;

(3) Treatments for depression should modify affective perception, affective cognitive control, or affective learning, although different modalities of treatments may operate on different processes: eg, antidepressant drugs may positively bias affective perception, whereas psychological therapies may alter negative affective cognitive control. Antidepressant drugs should positively bias affective information processing in both healthy volunteers and in depressed individuals;

(4) Changes in negative affective biases in those who are ultimately going to benefit from treatment should be detectable early in the course of treatment. However, as the cognitive processes altered by psychological therapies and antidepressant drug treatments may be different, cognitive predictors of response to these two treatment modalities may also be different;

(5) Early intervention in at-risk individuals (eg, cognitive training, medication) should prevent the incidence of illness by inhibiting the development of dysfunctional schemata.

Below we review the evidence pertaining to these predictions.

\section{DYSFUNCTIONAL AFFECTIVE COGNITIVE PROCESSING IN DEPRESSED PATIENTS}

\section{Emotional Perception}

Emotional disturbance is at the core of depressive symptomatology, and cognitive disturbances interact with the affective tone of stimulus material. Affective processing biases are apparent behaviorally in several domains of cognitive processing, including perception, attention, memory, and reward/feedback processing. Deficits in the perception or identification of facial emotions have been reported consistently in depression (Persad and Polivy, 1993; Rubinow and Post, 1992), although the exact nature of the abnormality varies. Some have argued for a general decrease in sensitivity to emotional faces (Leppanen, 2006; Mikhailova et al, 1996; Rubinow and Post, 1992) whereas others have argued for an overall negative bias compared with controls (Gur et al, 1992; Surguladze et al, 2004). For example, Gilboa-Schechtman et al (2002) reported both greater sensitivity to sad faces and greater response bias toward labeling faces as sad. Conversely, other studies have suggested that depressed patients show reduced sensitivity toward happy faces (Joormann and Gotlib, 2006; Murphy et al, 2009; Yoon et al, 2009).

Some of these discrepancies may reflect differences in the precise requirements of different emotion perception tasks. Similar discrepancies exist in the neuroimaging literature, which broadly focuses on aberrant amygdala responses to facial emotion or emotionally valent pictures (eg, from the 
International Affective Picture System: IAPS) in depression. Some fMRI studies have reported enhanced amygdala response to negative faces (Fu et al, 2004, 2008; Sheline et al, 2001; Surguladze et al, 2005) even in the absence of awareness (Suslow et al, 2010; Victor et al, 2010), but this pattern has not always been replicated (Dannlowski et al, 2008; Gotlib et al, 2005; Keedwell et al, 2005; Lawrence et al, 2004). Biased responses in other brain regions have also been reported, but again these vary between studies. Crucial factors underpinning these discrepancies include task characteristics (eg, overt $v s$ incidental $v s$ covert processing of emotion) and patient characteristics (notably medication status). Overall, the balance of evidence suggests a relative bias away from positive and toward negative emotional perception in depression, mediated by abnormal responses within the extended limbic system, in particular the amygdala.

\section{Emotional Attention}

Negative biases have also been observed on attentional tasks (see Gotlib et al, 2004a, b; Gotlib and Joormann (2010) for a review). In emotional Stroop tasks, depressed patients tend to take longer to name the color of negative emotional words (Broomfield et al, 2007; Gotlib and Cane, 1987; Gotlib and McCann, 1984; Segal et al, 1995; see Williams et al (1996) for a review), whereas in an affective go/no-go task, depressed patients, including first episode-depressed adolescents, were slower to respond to happy targets (Erickson et al, 2005; Kaplan et al, 2006; Kyte et al, 2005; Murphy et al, 1999). Some studies have suggested that depressed patients fail to display a bias toward positive emotional material, whereas such a bias is detectable reliably in healthy volunteers (McCabe and Gotlib, 1995). Visual search (Rinck and Becker, 2005) and dot-probe tasks with either words (Mathews et al, 1996) or faces (Gotlib et al, 2004b; Joormann and Gotlib, 2007) have also revealed negative attentional biases in depressed patients. However, an important caveat to these findings is that negative biases have typically not been detected when stimulus presentations are very brief (Mogg et al, 1993, 1995). Hence, some investigators suggest that the negative attentional biases identified at longer stimulus durations are driven by a difficulty in disengaging from negative stimuli, as opposed to a tendency to allocate greater attentional resources to them initially (Gotlib and Joormann, 2010). Consistent with the notion of impaired attentional disengagement from negative stimuli, neuroimaging studies primarily emphasize a role for the prefrontal cortex, especially perigenual ACC, including Brodmann areas 24, 25 , and 32, in mediating negative attentional biases in depression. Mitterschiffthaler et al (2003) reported enhanced perigenual ACC response to negative words in an emotional Stroop task, and similar findings have been reported for the affective go/no-go (Elliott et al, 2002). Several fMRI studies also suggest that in attentional contexts, enhanced lateral inferior frontal cortex response is associated with the impaired ability to divert attention from task-irrelevant negatively toned information (Dichter et al, 2009a; Elliott et al, 2002; Wang et al, 2008).

\section{Emotional Memory}

Depression is also associated with negative biases in memory tasks (Gur et al, 1992; Matt et al, 1992; Mogg et al, 1995). Again, this bias can be manifest either as a bias toward negative material or as a bias away from positive material. Thus, some studies find that depressed patients tend to preferentially remember negative stimuli (Bradley et al, 1995, 1996; Direnfeld and Roberts, 2006; Dunbar and Lishman, 1984; Rinck and Becker, 2005) whereas others find that patients do not show the normal bias toward remembering positive material exhibited by non-depressed individuals (Ellwart et al, 2003; Gilboa-Schechtman et al, 2002; Gotlib et al, in press; Harmer et al, 2009b). Again, specific task characteristics may be an important contributory factor in these different results. For example, Barry et al (2006) suggested that higher-level conceptual memory tasks are more likely to elicit biases than purely perceptual tasks. Neuroimaging studies suggest that these biases are mediated by limbic regions, including the amygdala; depressed patients showed greater right amygdala response and enhanced amygdala-hippocampal connectivity to subsequently remembered negative pictures (Hamilton and Gotlib, 2008).

\section{Reward and Punishment Processing}

Another area in which affective biases contribute to cognitive function in depression is in response to performance feedback, reward, and punishment (see Eshel and Roiser (2010) for a review). It has been proposed that depressed patients may show exaggerated responses to negative performance feedback (Elliott et al, 1997; Murphy et al, 2003). Neuroimaging studies suggest this effect may be mediated by relatively enhanced amygdala response (Taylor Tavares et al, 2008) and attenuated dorsal ACC response (Steele et al, 2007) to feedback. However, somewhat paradoxically, a recent study found that depressed individuals reported less intense feelings of regret than did healthy volunteers after negative feedback, a tendency that was particularly pronounced in individuals with high levels of anhedonia (Chase et al, 2010a). Studies have also assessed responses to rewards and reward-related learning. Reward processing in depression has not been widely studied using neuropsychological tasks, although reduced reward responsiveness has been observed behaviorally in some studies (Henriques and Davidson, 2000; Robinson et al, in press; Pizzagalli et al, 2008). In this latter study, reduced responsiveness was related to the specific symptom of anhedonia, a relationship also observed by Chase et al (2010b) in depressed patients.

The functional neuroimaging literature on reinforcement processing in depression is considerably more extensive with reports of reduced response to reward in the amygdala 
and striatal regions (Pizzagalli et al, 2009; Wacker et al, 2009), which may reflect attenuated reward prediction error signaling (Gradin et al, 2011), although this finding has not always been replicated (Knutson et al, 2008). Forbes et al (2009) reported that the degree of striatal response to reward predicted real-life measures of positive affect in depressed patients. Reduced amygdala/striatal response and enhanced perigenual ACC response to rewards is the opposite pattern to that described for negative feedback above, suggesting a valence-specific imbalance in the response of these regions. However, it should be noted that many of the above studies used experimental paradigms in which the presence of negative feedback was confounded with the absence of positive feedback, making it difficult to draw firm conclusions from this literature. In those studies that did examine reward and punishment processing independently, abnormal reward processing has been reported more commonly (Knutson et al, 2008; Pizzagalli et al, 2009; Wacker et al, 2009).

\section{The Influence of Cognitive Control}

Negative affective processing biases may depend on both enhanced 'bottom-up' responses to emotionally salient stimuli and poorer 'top-down' cognitive control mechanisms, required to suppress responses to emotionally valenced but task-irrelevant information (Clark et al, 2009; Phillips et al, 2003b). Such cognitive control mechanisms include being able to attend selectively, ignoring distracting information, being able to disengage attention from stimuli quickly when they cease to be relevant, and being able to store and manipulate stimulus representations online when they have disappeared. Numerous studies have reported deficits on tests involving cognitive control in depressed patients (see Castaneda et al (2008) for a review; Channon et al, 1993; Elliott et al, 1996; Taylor Tavares et al, 2007), and neuroimaging studies support these behavioral findings (Desseilles et al, 2009; Siegle et al, 2007).

Do cognitive control deficits in depression contribute to negative affective biases? Several studies have reported that negative emotional stimuli interfere with cognitive control in behavioral tasks (Joormann et al, 2010a, b; Joormann and Gotlib, 2008, 2010). Two studies have tested this hypothesis explicitly using fMRI. Fales et al (2008) used an attentional interference task with emotional distracters. Amygdala responses to unattended negative stimuli were increased in depressed patients relative to controls, but actively ignoring negative stimuli failed to engage prefrontal regions, consistent with a deficit in cognitive control. Dichter et al (2009b) used an emotional oddball task, finding that depressed patients exhibited greater PFC responses when required to disengage from processing negative stimuli. These studies suggest that abnormal PFC function may mediate poor cognitive control in depression, which contributes to negative affective biases. However, more work is required in this field, in particular to determine whether low- and high-level negative affective biases are related to each other.

In summary, the emotional biasing of cognition in depression occurs at various levels of processing. Biases both toward negative information and away from positive information may be important. At the neural level, enhanced responses to negative information are observed in regions of an extended limbic system (including the amygdala, hippocampus, and perigenual ACC). There is also reduced response of lateral prefrontal regions and dorsal ACC in situations in which responses to task-irrelevant emotional information must be suppressed, potentially suggesting a failure of cognitive control mechanisms.

\section{DYSFUNCTIONAL COGNITIVE PROCESSING IN INDIVIDUALS AT RISK FOR DEPRESSION}

Although numerous studies have detected negative affective biases in currently depressed patients, there is less evidence for such biases before development of depression, or indeed that negative affective biases predict subsequent mood disturbance. In particular, we are aware of only one published study that has attempted to predict the subsequent development of depression in high-risk individuals on the basis of negative affective processing biases (decreased sensitivity to reward predicted future depressive episodes: Forbes et al, 2007). This may be due to the challenging longitudinal experimental designs required, as never-depressed at-risk individuals, who in all other respects would be considered healthy volunteers, cannot be recruited and followed up through clinical services in the same manner as depressed patients. Nonetheless, several studies examining negative affective biases in individuals at risk for depression have been performed. These are of critical importance, as they speak to a question about which the cognitive neuropsychological model of depression makes a clear prediction: are negative affective biases in depressed patients a cause or a consequence of symptoms?

\section{Neuroticism and Affective Biases}

Together with stressful life events and genetic liability, one of the most well-established risk factors for depression in individuals who have never suffered from a depressive episode is neuroticism, a personality trait closely related to anxiety (Kendler et al, 1993, 2002). In addition, longitudinal studies have demonstrated that neuroticism seems to increase after recovery from a depressive episode relative to before the episode (the 'scar' effect: Kendler et al, 1993). Neuroticism is reliably elevated in first-degree relatives of depressed patients (Hecht et al, 2005; Ouimette et al, 1996; Rothen et al, 2009). Consistent with the cognitive neuropsychological model of depression, neuroticism is also inversely associated with central serotonin function (Flory et al, 2004).

There exist numerous demonstrations that highly neurotic never-depressed individuals exhibit negative affective 
processing biases. Negative biases have been reported in the cognitive domains of perception (Chan et al, 2007; Fruhholz et al, 2010), learning/memory (Bradley and Mogg, 1994; Martin et al, 1983; Rijsdijk et al, 2009; Ruiz-Caballero and Bermudez, 1995), and reward/feedback processing (Forbes et al, 2007; Robinson et al, 2010), although not attention (Chan et al, 2007; Rijsdijk et al, 2009). This lack of negative attentional biases in individuals at high risk of developing depression speaks to a subtle but important difference between the cognitive neuropsychological model and traditional psychological models of depression. Traditional psychological models propose that all negative affective biases are driven by the negative schemata (Beck, 1976). In the cognitive neuropsychological model, the causal process is the other way around: lower-level 'bottom-up' negative affective biases (eg, perceptual) drive the development of the negative schemata, which themselves may subsequently engender 'top-down' biases (eg, attentional). Hence, the presence of negative perceptual (ie, 'bottom-up') biases coincident with an absence of negative attentional (ie, 'top-down') biases in individuals at high risk for depression is more consistent with the cognitive neuropsychological model than traditional psychological models of depression.

Brain imaging studies have reported that more neurotic individuals display heightened responses to negative emotional stimuli in limbic regions such as the amygdala (Canli et al, 2001; Chan et al, 2009; Haas et al, 2007, 2008; Hooker et al, 2008; Stein et al, 2007), along with impaired connectivity between limbic regions and ventral aspects of the prefrontal cortex (eg, the subgenual ACC) (Cremers et al, 2010; Pezawas et al, 2005).

\section{Affective Biases in Individuals at Genetic Risk for Depression}

Although fewer investigations of negative affective processing in first-degree relatives of patients with depression have been performed, convergent results with the literature on neuroticism have emerged. This pattern might not be surprising, as relatives of depressed patients also tend to score higher on measures of neuroticism (Kendler et al, 1993, 2002). A few studies have identified negative affective biases in first-degree relatives of depressed patients (Joormann et al, 2010a; Joormann et al, 2007; Le Masurier et al, 2007; Mannie et al, 2007). Again, these findings are complemented by neuroimaging investigations that identified increased responsiveness to negative emotional stimuli in the amygdala (Monk et al, 2008; van der Veen et al, 2007; although see Mannie et $a l, 2011$ ) and reduced ventral striatal responsiveness to reward (Foti and Hajcak, 2011; Gotlib et al, 2010). In addition, close relatives of depressed patients have less efficient activation of parietal and temporal networks during working memory performance (Mannie et al, 2010), consistent with impaired cognitive control representing a vulnerability factor for developing depression.

A small number of studies have examined the effects of genetic polymorphisms believed to confer risk for depression on negative affective biases in never-depressed individuals. The polymorphism most often examined is the serotonin transporter-linked polymorphic region (5-HTTLPR), which alters in vitro (Hu et al, 2006), although possibly not in vivo (Murthy et al, 2010) expression of the serotonin transporter, the target of SSRIs. Carriers of the 5-HTTLPR $s$ allele, which is associated with increased vulnerability to depression (Clarke et al, 2010), especially in the context of stressful life events (Caspi et al, 2003; Gibb et al, 2009; although see Risch et al (2009)), have been reported to exhibit negative affective biases (Beevers et al, 2011; Fox et al, 2009; Hayden et al, 2008; Kwang et al, 2010; Perez-Edgar et al, 2010). However, findings are inconsistent, as other studies have reported no negative affective biases in $s$-allele carriers (Roiser et al, 2005, 2007) or only demonstrated biases under conditions of induced stress (Markus and De Raedt, 2011) or tryptophan depletion (Roiser et al, 2006). Like highly neurotic individuals and relatives of depressed patients, carriers of the $s$ allele also exhibit hyperactivation of the amygdala (Hariri et al, 2002; see Munafo et al (2008) for meta-analysis).

\section{Affective Biases in Recovered Depression}

Individuals who have previously suffered from a major depressive episode but subsequently recovered are at considerably increased risk for developing further episodes (Kendler et al, 1993). As such, studying recovered depressed individuals, particularly in the unmedicated state, might provide important insights into the cognitive mechanisms underpinning depression (Bhagwagar and Cowen, 2008). The literature investigating negative affective biases in recovered depressed patients is rather mixed (Leppanen, 2006). For example, behavioral biases toward negative stimuli or away from positive stimuli persisting into remission have been reported for emotion face perception (Anderson et al, in press; Bhagwagar et al, 2004; Fritzsche et al, 2010; LeMoult et al, 2009; Leppanen et al, 2004) and for attentional processing in a dot-probe task (Joormann and Gotlib, 2007). However, some have reported qualitatively distinct emotional face perception in recovered patients compared with currently depressed individuals (Anderson et al, in press). Other studies have reported persistent negative biases only if a transient negative mood is induced in remitted patients (Ramel et al, 2007; Timbremont and Braet, 2004). Negative mood induction is also associated with altered neural responses in remitted depressed patients during emotional faces processing (Gemar et al, 2007; Liotti et al, 2000) or words (Ramel et al, 2007). In the absence of mood induction, some brain imaging studies reported persistent abnormalities of amygdala response to negative faces in recovered patients (Kaplan et al, 2006; Victor et al, 2010), although others have not shown this effect (Thomas et al, 2011). This discrepancy might reflect differences in patient characteristics. Thomas et al (2011) reported that neural responses to negative faces in remitted patients were associated with trait rumination, 
such that those with lower levels of rumination (and therefore potentially less likely to relapse) showed reduced responses to sad faces compared with patients with higher levels of rumination. The low ruminators also tended to be less responsive to sad faces than healthy volunteers, consistent with the observation that remitted patients who were able to remain well off medication for an extended period may demonstrate a positive bias in emotional processing (Gotlib and Cane, 1987; Roiser et al, 2009). Finally, impaired cognitive control also seems to persist in remitted depressed patients (Paelecke-Habermann et al, 2005; Preiss et al, 2009; Smith et al, 2006), suggesting that 'top-down' processes might mediate biases in recovered as well as in currently depressed patients.

In summary, studies have reported that individuals at risk for depression, whether by virtue of high neuroticism, genetic risk or previously having suffered from a depressive episode, exhibit low-level negative affective biases that are qualitatively similar to those present in the depressed state. However, it is not yet clear whether high-level biases (eg, negative cognitive control) exist in high-risk individuals before the onset of depression: the model outlined in this paper predicts that they should not. Finally, the evidence pertaining to negative biases in individuals in remission from depression is more mixed, with some studies reporting negative biases and others positive biases. These discrepant results may reflect differences in patient characteristics.

\section{EFFECTS OF TREATMENTS FOR DEPRESSION ON AFFECTIVE PROCESSING}

If negative affective biases are the source of the cognitive schemata that stimulate and maintain depressive symptoms, then successful treatments should alter such biases, and changes should be evident even before patients' symptoms begin to improve (Clark et al, 2009; Harmer et al, 2009a). In addition, the effects of treatments for depression on affective biases may also be observable in healthy volunteers (Harmer, 2008). Experimental research is now beginning to address these questions.

\section{Antidepressant Medication Effects on Affective Processing in Healthy Volunteers}

Perturbations of monoamine systems have long been known to alter behavior on tests of affective processing in healthy volunteers. For example, tryptophan depletion, which is believed to reduce central serotonin synthesis, impairs reward processing (Rogers et al, 2003) and abolishes positive attentional biases in healthy volunteers (Murphy et al, 2002). Conversely, administration of antidepressant drugs targeting the serotonin (eg, citalopram) or noradrenaline (eg, venlafaxine) systems enhances positive biases in healthy volunteers when administered subchronically (eg, for 7-14 days: Harmer et al, 2004). However, single-dose studies have yielded less clear results, with some reporting enhanced fear processing and others reporting more positive biases after SSRI administration (Grillon et al, 2007; Harmer et al, 2003a, b; see Pringle et al (2010) for a review). The explanation for this inconsistency is not yet clear, but may be related to early anxiogenic effects sometimes observed during treatment in depressed patients; possibly a specific subgroup of individuals is particularly vulnerable to these effects (Harmer et al, in press).

The ability of monoamine medications to positively bias affective processing is broadly supported by brain imaging findings (Harmer et al, 2009a), although with one discrepancy. Several pharmacological fMRI studies have reported that even single-dose antidepressant administration in healthy volunteers reduces amygdala (Anderson et al, 2007; Harmer et al, 2006; Murphy et al, 2009; Norbury et al, 2007) and prefrontal (Miskowiak et al, 2007; Norbury et al, 2008) responses to negative stimuli (including fearful faces), and increases responses to positive stimuli (Anderson et al, 2011; Norbury et al, 2009). This pattern is in line with the prediction that these drugs positively bias affective processing (Harmer et al, 2009a), although it raises the question of why some single-dose behavioral studies reported greater sensitivity to negative stimuli (Pringle et al, 2010). Possibly this pattern of results might reflect sample selection, as individuals who are highly anxious may be less likely to participate in fMRI experiments (Harmer et al, in press); however, this hypothesis has yet to be tested explicitly. The few subchronic studies (ie, using dosing regimes of up to 2 weeks) that have been performed with fMRI yielded comparable results to single-dose studies (Arce et al, 2008; van Marle et al, 2011).

Few fMRI studies investigating the effects of monoamine manipulations on reward processing have been performed. Interestingly, one found different effects of subchronic serotonin and noradrenaline manipulation on rewardrelated responses in the ventral striatum and orbitofrontal cortex (McCabe et al, 2010). Although 7 days of citalopram reduced responses to both appetitive and aversive stimuli (sweet and rotten flavors), 7 days of reboxetine only reduced responses to aversive stimuli. This pattern is consistent with reports that SSRIs can cause emotional blunting in some patients, whereas this side effect is less common with SNRI treatment (Price et al, 2009). Supporting this notion, another study reported reduced striatal reward prediction error signals in healthy volunteers administered SSRIs (Kumar et al, 2008).

\section{Antidepressant Medication Effects on Affective Processing in Depressed Patients}

According to the cognitive neuropsychological model of depression, the main beneficial effect of antidepressant drug action is to eliminate or reverse negative affective biases in depressed patients. Therefore, a strong prediction of this model is that negative affective processing biases should be altered in depressed patients with successful treatment (Clark et al, 2009; Harmer et al, 2009a). Moreover, such 
changes should be observable early in the course of treatment in patients who will subsequently remit. However, remarkably few studies have addressed this question, and to our knowledge none have examined behavioral measures of affective biases before and after treatment in a longitudinal design. With respect to early effects of treatment, Tranter et al (2009) reported that reboxetine and citalopram increased recognition not only of happy faces but also disgust and surprise, 2 weeks after treatment commencement; the authors note that these improvements might simply be due to practice. However, the degree of improvement in the recognition of happy faces did correlate with subsequent response to treatment, consistent with the cognitive neuropsychological model. Using a single-dose design, Harmer et al (2009b) reported that reboxetine ameliorated negative perception and memory biases in unmedicated depressed patients. The available brain imaging data are consistent with this behavioral effect: Keedwell et al (2010) found that deactivation to negative faces in the subgenual ACC after 2 weeks of treatment was predictive of poorer mood response at 8-16 weeks.

A greater number of studies have investigated the effects of antidepressant medication on affective processing biases in depression before and after treatment using fMRI. These studies have reported remarkably reliable results since Sheline et al (2001) first identified reduced amygdala responses to negative faces in depressed patients after SSRI treatment relative to before treatment, even when stimuli were presented outside visual awareness (using a masking procedure). This initial finding, which was not observed in untreated healthy volunteers scanned twice over the same time period, has been replicated in studies using similar designs (Anand et al, 2007; Fu et al, 2004), including in one study that featured a placebo arm in depressed patients (Victor et al, 2010). Effects on responses in brain regions other than the amygdala have also been reported, eg, in the subgenual cingulate (Keedwell et al, 2009). Fu et al (2007) also reported increased visual cortex responses to happy faces after antidepressant treatment, which correlated with the degree of mood improvement. Studies treating with SNRIs have reported similar effects for both negative and positive stimuli, especially in the perigenual ACC, a region with extensive reciprocal connections with the amygdala and other prefrontal regions (Davidson et al, 2003; Kalin et al, 1997; Schaefer et al, 2006).

Some studies have suggested that prefrontal-limbic connectivity increases after antidepressant administration (Anand et al, 2005, 2007; Chen et al, 2008). Although these results would be consistent with increased top-down control of emotional processing after treatment, it should be noted that the methods used to assess functional connectivity in these studies cannot determine the direction of connectivity; additionally, most examined connectivity over the entire fMRI time series, precluding consideration of valencespecific changes. Only one study (Anand et al, 2005) examined whether antidepressant administration alters valence-specific changes in connectivity. They found that
ACC-amygdala connectivity remained abnormally low in depressed patients during the processing of negative stimuli even after sertraline treatment, although connectivity during the resting state increased (Anand et al, 2007). Inefficient recruitment of prefrontal and parietal regions during working memory performance also seems to persist after successful SSRI treatment (Schoning et al, 2009; Walsh et al, 2007), consistent with the notion that impaired cognitive control may be an enduring feature of depressive illness, and is not remediated by antidepressants.

\section{Predicting Response to Antidepressant Treatment using Affective Processing}

The results discussed above raise the question of whether it might be possible to predict response to antidepressants based on affective processing biases before commencement of treatment. Unfortunately, most of the studies discussed above did not report the results of such an analysis. Nonetheless, a number of studies have implicated the perigenual ACC (including subgenual, pregenual, and dorsal ACC: Brodmann areas 24, 25, and 32) in response to antidepressant treatment. Two groups, using drugs targeting different monoamine systems, reported that perigenual ACC deactivation to negative stimuli at baseline was predictive of subsequent poorer antidepressant treatment response (Chen et al, 2007; Davidson et al, 2003); reduced connectivity between the adjacent orbitofrontal cortex and caudate during emotional processing has also been linked to poor venlafaxine response (Lisiecka et al, 2011). Interestingly, a recent study reported that increased perigenual ACC response while viewing sad film clips in medicated remitted depressed patients was associated with relapse 18 months later (Farb et al, 2011). Consistent with a role for perigenual ACC in recovery from depression, several PET studies reported that increased resting-state glucose metabolism in this region at baseline was predictive of poor outcome after antidepressant drug treatment (Kegeles et al, 2003; Konarski et al, 2009; Mayberg et al, 1997).

To our knowledge, only two studies have used behavioral measures of affective processing to predict which patients will respond to antidepressant drug treatment, although their results are difficult to interpret as some patients were taking antidepressant medication at baseline (Rottenberg et al, 2005; Johnson et al, 2007; see later discussion). In keeping with a possible role for cognitive control in recovery from depression (Gotlib and Joormann, 2010), several studies reported that poor performance on tests of cognitive control was associated with poor response to antidepressant drug treatment (Baldwin et al, 2004; Gudayol-Ferre et al, 2010; Kalayam and Alexopoulos, 1999; Kampf-Sherf et al, 2004; Potter et al, 2004). This finding is consistent with a report that lower dorsal ACC responses during working memory performance (interpreted as indicating more efficient processing) predicted better response to antidepressant treatment (Walsh et al, 2007). 


\section{Effects of Psychological Therapies on Affective Processing}

Although there has been less research on the effects of psychological therapies on affective processing in depression, the results of those studies that have been conducted provide an interesting complement to the psychopharmacological data discussed above. Although no studies have yet reported behavioral measures of affective biases before and after psychological treatment to our knowledge, some fMRI studies have been conducted. One advantage of studying individuals undergoing psychological therapy is that the participants are usually unmedicated, avoiding potential for the effects of medication on neurovascular coupling to confound results (Schleim and Roiser, 2009). Only two studies have investigated the effects of psychological therapy on emotional processing in depression using fMRI in a longitudinal design. Fu et al (2008) reported that CBT attenuated amygdala responses and enhanced perigenual ACC responses to negative faces, such that posttreatment patients and controls no longer differed in these regions. Ritchey et al (2011) reported a strikingly similar pattern of results, using IAPS pictures instead of faces.

Two studies have investigated reward processing before and after psychological therapies. Dichter et al (2009a) found increased striatal responses during a gambling game after BA, a psychological therapy specifically targeted at decreasing engagement with punishing stimuli and increasing engagement with rewarding ones. However, whether this finding might be related to the reward-processing aspects of BA per se is unclear, as another study reported that increased striatal responsiveness during reward processing predicted future improvement after CBT (Forbes et al, 2010). However, although the changes observed in the studies discussed above were not observed in healthy volunteers over the same time period, none included a control condition in depressed patients, raising the possibility that non-specific temporal effects might have influenced the results in the depressed patient group.

\section{Predicting Response to Psychological Therapy using Affective Processing}

Some of the studies discussed above also addressed the question of predicting response to psychological therapy. In one study, the greater the response to negative stimuli in the left ventrolateral and right dorsolateral PFC, the greater the subsequent improvement in symptoms (Ritchey et al, 2011). Another study also showed this effect in the right dorsolateral PFC, but in the left dorsolateral and left ventrolateral PFC and dorsal perigenual ACC, the opposite relationship applied (ie, greater deactivation to negative stimuli predicted better response: Fu et al, 2008). Using a multivariate pattern analysis approach, the same authors found that responses to negative faces in similar regions predicted subsequent recovery from depression (Costafreda et al, 2009).

Other investigators reported a similar relationship between pre-treatment response to negative stimuli in the perigenual ACC and subsequent benefit from psychological therapies (Dichter et al, 2010; Siegle et al, 2006). Siegle et al (2006) reported that response to CBT was associated with greater amygdala response and greater perigenual ACC deactivation before treatment. Similarly, Dichter et al (2010) reported that greater dorsal perigenual ACC responses during an attentional task featuring negative distractors predicted better subsequent response to BA (see Figure 2). Interestingly, a recent study found that lower pupil dilation to negative stimuli was strongly predictive of response to psychological therapy, as were reduced prefrontal responses (Siegle et al, 2011). As with response to antidepressant medications, a role for perigenual ACC in mediating response to psychological therapies is supported by longitudinal PET studies (Kennedy et al, 2007; Konarski et al, 2009).

\section{Effects of Less Common Treatments on Affective Processing}

Finally, some studies have begun to investigate the cognitive effects of more experimental antidepressant approaches. Mood response to sleep deprivation (a highly effective intervention that unfortunately lasts only until patients fall back to sleep) was consistently predicted by pre-treatment resting-state hypermetabolism in the perigenual ACC measured using PET (see Gillin et al (2001) for a review), and a similar finding was reported in the amygdala (Clark et al, 2006). So far as we are aware, behavioral and neural responses to negative stimuli have so far not been investigated in such studies in depressed patients after sleep deprivation. However, a recent study in healthy volunteers reported that sleep deprivation increased positive ratings of pictures, and increased response to positive stimuli in the amygdala, putamen, and dopaminergic midbrain (Gujar et al, 2011). Salvadore et al reported that greater perigenual ACC responses to negative faces (2009) and ACC-amygdala connectivity during a working memory task (Salvadore et al, 2010) both predicted greater improvement after ketamine administration. Although DBS in the subgenual ACC was reported to improve cognitive performance on some measures in a case series (McNeely et al, 2008), and to reduce perigenual ACC metabolism (Mayberg et al, 2005), effects on measures of affective processing have not yet been reported.

Consistent with the notion that cognitive control may have a key role in recovery from depression, modafinil, which improves working memory in healthy volunteers (Turner et al, 2003), has been reported to boost the antidepressant effect of fluoxetine (Abolfazli et al, 2011; DeBattista et al, 2004; Fava et al, 2005; Rasmussen et al, 2005). However, the cognitive mechanisms underpinning this effect have yet to be clarified. Possibilities include improved cognitive control, as demonstrated in chronic schizophrenia and attention deficit hyperactivity disorder patients after single-dose modafinil administration (Turner et al, 2004a, b) or even a direct effect on emotional processing, as recently demonstrated in first-episode psychosis patients (Scoriels et al, 2011). 


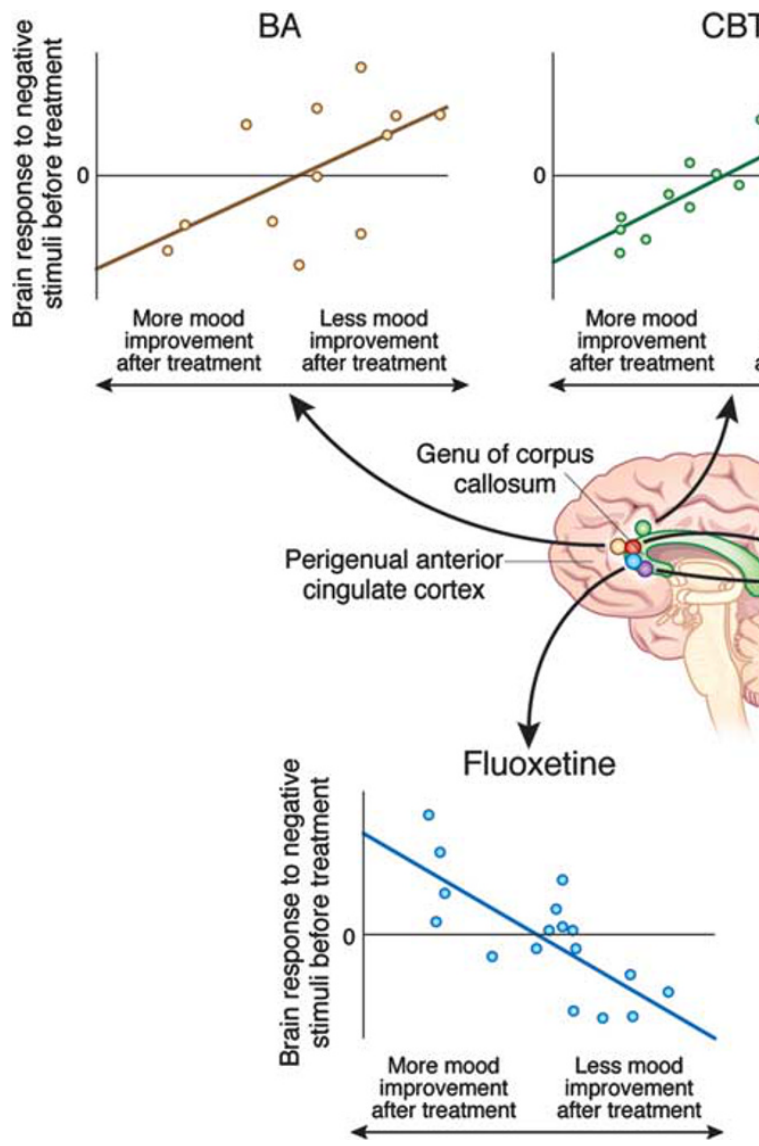

CBT

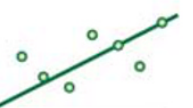

CBT
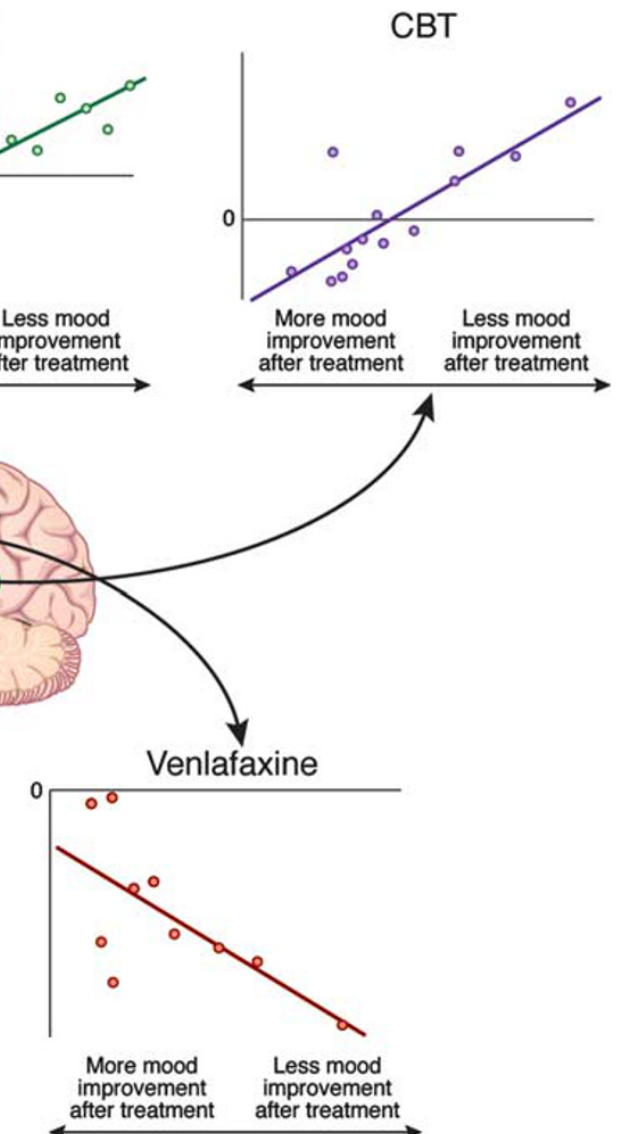

Figure 2. Hemodynamic responses to negative stimuli in the perigenual anterior cingulate cortex (ACC) predict subsequent response to treatment in depression, but in different directions for pharmacological and psychological treatments. Individuals with greater perigenual ACC responses to negative stimuli have greater mood improvement after treatment with fluoxetine or venlafaxine, whereas the converse is true for responders to cognitive behavioral therapy (CBT) and behavioral activation therapy (BA) (see also DeRubeis et al (2008)). Data redrawn from Chen et al (2007-blue), Davidson et al (2003 - red), Dichter et al (2010 — yellow), Fu et al (2008 — green) and Siegle et al (2006 — purple). It must be noted that all studies other than one (Davidson et al, 2003) measured change from baseline in symptoms. Davidson et al (2003) included only symptoms after treatment, but reported that there was no correlation between baseline severity and perigenual ACC response to negative stimuli.

In summary, antidepressant drugs bias affective processing positively in patients with depression, and effects seem to be detectable early in the course of treatment. Similar results have been reported in healthy volunteers, although there have been some conflicting reports regarding the effects of acute dosing. Psychological therapies have also been reported to bias affective processing positively, but only a handful of relevant reports exist and more research is required in this area. Finally, initial results tentatively suggest that it might be possible to predict whether a depressed patient is more likely to respond to antidepressant drug treatment or to psychological therapy depending on their perigenual ACC response to negative stimuli (see DeRubeis et al (2008) and Figure 2).

\section{FUTURE DIRECTIONS AND CLINICAL IMPLICATIONS}

The past decade has seen an explosion of research into cognitive abnormalities in depression, much of which has focused on understanding the negative affective biases that are hypothesized to have a central causal role in the generation of dysphoria and anhedonia (Clark et al, 2009; Harmer et al, 2009a; Robinson and Sahakian, 2008; Sahakian and Morein-Zamir, 2011). However, many questions remain unanswered, in particular relating to the possible clinical benefits that understanding the role of negative affective biases in depression might bring. Although there are hints in the literature that understanding cognitive abnormalities in depression might be useful in tailoring treatments on an individual patient basis, improving existing psychological therapies, helping to identify individuals at high risk for depression, and possibly even preventing the incidence of depression through early intervention, these predictions remain almost entirely untested. In this final section, we discuss some preliminary data pertaining to these questions, and make some recommendations for future research.

\section{Predicting Differential Response to Treatment}

When a depressed patient first contacts his or her doctor, a number of first-line treatment options are available, broadly 
falling into the monoamine medication or psychological therapy approaches, or some combination of the two. Some patients benefit greatly from medications, whereas psychological therapies have little impact; in others, the converse is true. Certain clinical characteristics such as severity, younger age of onset and chronicity (Hamilton and Dobson, 2002), as well as poor cognitive control (Gotlib and Joormann, 2010), are predictive of poor response to treatment generally. However, such variables have not generally been found to predict which treatment strategy is likely to be more beneficial for a given patient (Frank et al, 2011). Although it has been proposed that stratification by genotype may aid in the tailoring of treatment strategy on an individual basis (Serretti et al, 2007), the available data suggest that the discriminating power of individual genetic variants is likely to be too low to be of use clinically (Ising et al, 2009; Uher et al, 2010).

On the basis of findings that changes in negative affective biases in depressed individuals may occur very early during successful treatment (Harmer et al, 2009b; Tranter et al, 2009), it may be possible to use sub-chronic pharmacological challenges to predict which individuals are more likely to benefit from treatment with antidepressant medications. The cognitive neuropsychological model would predict that those individuals showing the greatest positive change in low-level affective processing after a short period of treatment (up to 1 week) should ultimately experience the greatest benefit after 6 weeks of treatment. Conversely, a lack of effect on affective processing after 1 week may indicate that other treatment approaches would likely be more successful. However, to our knowledge, no studies have yet investigated this question.

Could affective cognition be used to predict differential response to treatment with medication or psychological therapy even before treatment? On the basis of the model outlined above, it would be predicted that depressed individuals with more pronounced low-level (eg, perceptual) biases at baseline but with less pronounced high-level (eg, attentional) biases might respond best to antidepressant medication; the opposite pattern would be predicted for those who respond well to psychological therapies. Depressed individuals with both low- and high-level negative affective biases might experience the greatest benefit from a combination of medication and psychological therapy.

No study has yet addressed these predictions directly, but two reported that negative memory biases at baseline were associated with outcome after treatment with a mixture of antidepressant drug treatments and psychological therapy (Johnson et al, 2007; Rottenberg et al, 2005). However, the direction of the effect was inconsistent between these studies. Consistent with the central tenet of the cognitive neuropsychological model that monoamine medications exert their effects by attenuating or reversing low-level negative affective biases, Rottenberg et al (2005) reported that depressed individuals with a greater intensity of negative autobiographical memories at baseline showed the best response to antidepressant drug treatment; subgroup analysis including only individuals who were unmedicated at baseline confirmed this effect. By contrast, Johnson et al (2007) found that better memory for positive words predicted better subsequent treatment response 9 months later. As over one-third of the participants in the latter study were medicated at baseline, and no subgroup analyses were reported, it is possible that the negative biases had already been reversed in some medicated patients, who were still nonetheless depressed, explaining this apparent discrepancy with the cognitive neuropsychological model (also see Tranter et al (2009)). Further work is required using longitudinal designs in which depressed patients are unmedicated during baseline assessment to clarify the interpretation of these findings.

To our knowledge, no behavioral studies have yet investigated whether measures of affective bias can predict response to psychological therapies vs pharmacological therapies. However, fMRI studies using pre-treatment affective bias challenges have been undertaken, allowing a comparison of predictors of response to psychological vs pharmacological therapies at a neural level. Several studies have assessed whether pre-treatment neural responses to affective stimuli in the perigenual ACC can predict responses to treatment (Figure 2; see also DeRubeis et al (2008)). Two studies, using fluoxetine and venlafaxine, respectively, reported that greater perigenual ACC responses to negative stimuli pre-treatment, contrasting negative faces with 'baseline' fixation cross (Chen et al, 2007) or negative IAPS pictures with matched neutral stimuli (Davidson et al, 2003), predicted better subsequent mood response. By contrast, Siegle et al (2006) and $\mathrm{Fu}$ et al (2008) reported that lower pre-treatment responses (in fact deactivations relative to baseline) to negative words relative to neutral words in perigenual ACC predicted better response to CBT. A similar relationship was identified in a more dorsal perigenual ACC region by Dichter et al (2010), in a study using response to negative pictures to predict response to BA.

The contrast between higher perigenual ACC response to negative stimuli predicting a greater benefit from antidepressant medication, but lower perigenual ACC response predicting greater benefit from psychological therapy is striking (DeRubeis et al, 2008). This pattern is consistent with our proposal that psychological therapies exert their beneficial effects through enhancing affective cognitive control, as this subregion of the ACC is believed to be critically implicated in the implicit regulation of negative emotion, by its interaction with the amygdala (Etkin and Schatzberg, 2011). These data indicate that pre-treatment baseline response in the perigenual ACC may predict likely response to a given treatment, or even which treatment is more likely to be effective. However, it should be noted that these studies used different types of emotional stimuli (faces, pictures, and words), and had different task demands inside the scanner (gender classification, passive viewing, self-referential rating, and target detection), which complicates the interpretation of this apparent dissociation. Furthermore, the foci within the perigenual ACC that predicted response varied between the studies; even adjacent perigenual ACC regions are associated 
with distinct patterns of connectivity (Beckmann et al, 2009). There is a clear need for further studies examining and directly comparing predictors of both types of treatment response to test the hypothesis that neural responses to affective stimuli may represent biomarkers for differential treatment response.

\section{New Approaches to Treatment Based on the Cognitive Neuropsychological Model: A Role for Cognitive Enhancement?}

This review has focused on the important role for types of 'hot' (ie, emotionally laden) cognition in mediating the development and treatment of depressive symptoms. However, as the model we outline also suggests a key role for cognitive control in recovery from depression, especially with respect to the mechanism of action of psychological therapies, it is possible that 'cold' cognition (information processing without an affective component) might be a useful novel therapeutic target. Indeed, some clinicians have developed effective psychological therapies on this very basis: mindfulness-based CT (Teasdale et al, 1995, 2000) does not promote the challenging of negative automatic thoughts per se, but instead prevents them from escalating by encouraging patients to disengage from them to minimize their emotional impact, which could be conceptualized as a form of cognitive control. This is important because antidepressant drugs, whether targeting the serotonin or noradrenaline systems, generally have not been found to improve cognitive control (Chamberlain et al, 2006; Riedel et al, 2005).

The reliable finding that impaired cognitive control predicts poor response to treatment has already been used to motivate novel pharmacological approaches to treatment in depression. Modafinil, a cognitive enhancer (Turner et al, 2003), has been found to improve response to antidepressant treatment response in a number of studies (Abolfazli et al, 2011; DeBattista et al, 2004; Fava et al, 2005; Rasmussen et al, 2005). Whether this effect is mediated through improved cognitive control specifically has yet to be determined; it would also be of great interest to investigate whether the same benefit would be observed if modafinil was used as an adjunct to psychological therapy. However, some tangential evidence supporting the notion that improving cognitive control might improve depression has emerged from trials of cognitive training in patients with dementia. In several well-controlled trials, cognitive training targeting at relieving symptoms of dementia had the unexpected simultaneous effect of improving depressive symptoms (Davis et al, 2001; Loewenstein et al, 2004; see Sitzer et al (2006) for a review). However, further work is required to ascertain whether similar cognitive training in non-demented depressed individuals might improve symptoms.

It has also not yet been investigated whether circuitrybased interventions, including DBS in the subgenual cingulate cortex and TMS in the dorsolateral prefrontal cortex, might potentiate the effects of psychological therapies. Such an effect would be predicted from the cognitive neuropsychological model, as there is evidence that both of these interventions enhance activity in neural circuits subserving cognitive control (Lozano et al, 2008; Speer et al, 2000).

\section{Tailoring Psychological Therapies to Individual Patients}

Another question arising from our review is whether specific types of negative bias might be better treated by specific psychological therapies. We would predict that depressed patients exhibiting profound reward-processing deficits, which correlate with anhedonia (Chase et al, 2010b), would benefit more from psychological therapies focused on re-engaging in positively reinforcing activities, such as BA, than those focused on challenging negative schemata, such as CBT. Another important development in the field of psychological treatment is CBM, a therapy initially developed for anxiety (MacLeod et al, 2002; Matthews and MacLeod, 2002). Although research into CBM is still in its infancy, and different investigators have attempted to modify different cognitive processes (eg, attention $v s$ appraisal), several studies have reported beneficial results in dysphoric participants (see Hallion and Ruscio, in press for a review). A few studies have reported the effects of this technique on symptoms in depressed individuals, although with mixed results (Baert et al, 2010). We suggest that the scope of CBM might usefully be broadened to other domains of cognition, eg, reinforcement processing. In particular, it would be of great interest to examine whether reward reactivity and/or reward learning could be enhanced through CBM techniques, and whether manipulating reward processing might be beneficial in the treatment of anhedonia. Whether CBM and circuit-based interventions, such as rTMS, might work more efficaciously when used in combination is not yet known, but this is a result that would be predicted on the basis of the model outlined in this paper.

\section{Identifying and Treating Individuals at Risk for Depression}

A final important question is whether individuals who are at risk for developing depression might be identified on the basis of negative affective biases, and whether preventative measures (such as CBT or CBM) could be administered proactively, reducing the incidence of depression through resilience mechanisms (Elliott et al, 2010). Although such a strategy would require intensive resources, there are some preliminary data suggesting that this approach might be worthwhile (Koster et al, 2009). One large trial reported a substantial reduction in the incidence of depression using a CBT intervention in adolescent offspring of depressed parents (Garber et al, 2009). However, not all individuals who develop depression can be identified on the basis of genetic risk. Hence, negative affective biases may have an important role in future studies. 
In support of this notion, it has been reported that negative attentional biases in non-depressed individuals are strongly predictive of subsequent responses to stress (Fox et al, 2010). Moreover, interventions other than CBT may also be efficacious. For example, CBM has been reported to alter the processing of negative stimuli in healthy volunteers (Tran et al, 2011), an effect that appeared to be mediated by the lateral PFC in one study (Browning et al, 2010). The converse effect has also been demonstrated: MacLeod et al (2002) randomized individuals to receive training to attend preferentially to positive or negative stimuli using a dotprobe task. Those trained to attend to negative stimuli were subsequently more vulnerable to low mood after experimentally induced stress.

These findings raise the possibility that training individuals at risk for depression to process positive information preferentially using CBM could potentially help to prevent them from becoming ill (Matthews and MacLeod, 2002). Watkins et al (2009) reported that training dysphoric individuals to become more concrete and specific in their thinking reduced depressive symptoms, although follow-up was not conducted to determine whether the incidence of depression was decreased. Another study successfully trained depressed individuals to forget negative material using a 'think/no-think' procedure (Joormann et al, 2009), although again the long-term effects on symptoms was not assessed.

\section{CONCLUSIONS}

Depression is characterized by negative affective biases that may have a central role in the development of illness and response to treatment. These biases are also present in individuals at risk of illness, including those who are highly neurotic, have a close relative with depression, or have suffered from depression in the past. Preliminary data supporting the cognitive neuropsychological model of depression have demonstrated that antidepressant drugs can alleviate or even reverse negative affective biases, although further research is required using longitudinal designs in currently depressed patients. Future studies should address whether negative affective biases are able to predict which patients will respond well to specific treatment approaches (eg, pharmacological vs psychological treatment), and whether the incidence of depression might be reduced by programs aimed at modifying cognitive biases in individuals at high risk of illness. Preventing the development of depression and treating it early and effectively before it becomes a chronic, debilitating disorder must be a priority target for society and governments (Beddington et al, 2008; Collins et al, 2011; Sahakian et al, 2010).

\section{ACKNOWLEDGEMENTS}

We thank Steve Pilling for helpful discussions and for comments on the manuscript, and Rebecca Lawson for assistance with manuscript preparation.

\section{DISCLOSURE}

JPR, RE, and BJS all consult for Cambridge Cognition and BJS consults for a number of pharmaceutical companies. BJS's research is supported by a grant from The Wellcome Trust $(089589 / \mathrm{Z} / 09 / \mathrm{Z})$. The authors declare no conflict of interest.

\section{REFERENCES}

Abolfazli R, Hosseini M, Ghanizadeh A, Ghaleiha A, Tabrizi M, Raznahan M et al (2011). Double-blind randomized parallel-group clinical trial of efficacy of the combination fluoxetine plus modafinil versus fluoxetine plus placebo in the treatment of major depression. Depress Anxiety 28: 297-302.

Anand A, Li Y, Wang Y, Gardner K, Lowe MJ (2007). Reciprocal effects of antidepressant treatment on activity and connectivity of the mood regulating circuit: an FMRI study. J Neuropsychiatry Clin Neurosci 19: 274-282.

Anand A, Li Y, Wang Y, Wu J, Gao S, Bukhari L et al (2005). Antidepressant effect on connectivity of the mood-regulating circuit: an FMRI study. Neuropsychopharmacology 30: 1334-1344.

Anderson IM, Del-Ben CM, McKie S, Richardson P, Williams SR, Elliott R et al (2007). Citalopram modulation of neuronal responses to aversive face emotions: a functional MRI study. Neuroreport 18: 1351-1355.

Anderson IM, Juhasz G, Thomas E, Downey D, McKie S, Deakin JF et al (2011). The effect of acute citalopram on face emotion processing in remitted depression: a pharmacoMRI study. Eur Neuropsychopharmacol 21: 140-148.

Anderson IM, Shippen C, Juhasz G, Chase D, Thomas E, Downey D et al (in press) State-dependent alteration in face emotion recognition in depression. $\mathrm{Br} J$ Psychiatry.

Arce E, Simmons AN, Lovero KL, Stein MB, Paulus MP (2008). Escitalopram effects on insula and amygdala BOLD activation during emotional processing. Psychopharmacology (Berl) 196: 661-672.

Asberg M, Thoren P, Traskman L, Bertilsson L, Ringberger V (1976). 'Serotonin depression' - a biochemical subgroup within the affective disorders? Science 191: 478-480.

Baert S, De Raedt R, Schacht R, Koster EH (2010). Attentional bias training in depression: therapeutic effects depend on depression severity. J Behav Ther Exp Psychiatry 41: 265-274.

Baldwin R, Jeffries S, Jackson A, Sutcliffe C, Thacker N, Scott M et al (2004). Treatment response in late-onset depression: relationship to neuropsychological, neuroradiological and vascular risk factors. Psychol Med 34: 125-136.

Barry ES, Naus MJ, Rehm LP (2006). Depression, implicit memory, and self: a revised memory model of emotion. Clin Psychol Rev 26: 719-745.

Beck AT (1967). Depression: Clinical, Experimental and Theoretical Aspects. Harper \& Row: New York.

Beck AT (1976). Cognitive Therapy and Emotional Disorders. International University Press: New York. Explanation of the original formulation of the concepts of negative schemata and affective biases.

Beckmann M, Johansen-Berg H, Rushworth MF (2009). Connectivity-based parcellation of human cingulate cortex and its relation to functional specialization. $\checkmark$ Neurosci 29: 1175-1190.

Beddington J, Cooper CL, Field J, Goswami U, Huppert FA, Jenkins R et al (2008). The mental wealth of nations. Nature 455: 1057-1060.

Beevers CG, Marti CN, Lee HJ, Stote DL, Ferrell RE, Hariri AR et al (2011). Associations between serotonin transporter gene promoter region (5-HTTLPR) polymorphism and gaze bias for emotional information. J Abnorm Psychol 120: 187-197.

Bhagwagar Z, Cowen PJ (2008). 'It's not over when it's over': persistent neurobiological abnormalities in recovered depressed patients. Psychol Med 38: 307-313.

Bhagwagar Z, Cowen PJ, Goodwin GM, Harmer CJ (2004). Normalization of enhanced fear recognition by acute SSRI treatment in subjects with a previous history of depression. Am J Psychiatry 161: 166-168.

Bradley BP, Mogg K (1994). Mood and personality in recall of positive and negative information. Behav Res Ther 32: 137-141.

Bradley BP, Mogg K, Millar N (1996). Implicit memory bias in clinical and non-clinical depression. Behav Res Ther 34: 865-879.

Bradley BP, Mogg K, Millar N, White J (1995). Selective processing of negative information: effects of clinical anxiety, concurrent depression, and awareness. $J$ Abnorm Psychol 104: 532-536.

Broomfield NM, Davies R, MacMahon K, Ali F, Cross SM (2007). Further evidence of attention bias for negative information in late life depression. Int J Geriatr Psychiatry 22: 175-180. 
Browning M, Holmes EA, Murphy SE, Goodwin GM, Harmer CJ (2010). Lateral prefrontal cortex mediates the cognitive modification of attentional bias. Biol Psychiatry 67: 919-925. Neuroimaging study demonstrating the neural mechanisms of change in affective bias following cognitive bias modification.

Canli T, Zhao Z, Desmond JE, Kang E, Gross J, Gabrieli JD (2001). An fMRI study of personality influences on brain reactivity to emotional stimuli. Behav Neurosci 115: 33-42.

Caspi A, Sugden K, Moffitt TE, Taylor A, Craig IW, Harrington H et al (2003). Influence of life stress on depression: moderation by a polymorphism in the 5HTT gene. Science 301: 386-389.

Castaneda AE, Suvisaari J, Marttunen M, Perala J, Saarni SI, Aalto-Setala T et al (2008). Cognitive functioning in a population-based sample of young adults with a history of non-psychotic unipolar depressive disorders without psychiatric comorbidity. J Affect Disord 110: 36-45.

Chamberlain SR, Muller U, Blackwell AD, Robbins TW, Sahakian BJ (2006). Noradrenergic modulation of working memory and emotional memory in humans. Psychopharmacology (Berl) 188: 397-407.

Chan SW, Goodwin GM, Harmer CJ (2007). Highly neurotic never-depressed students have negative biases in information processing. Psychol Med 37: 1281-1291.

Chan SW, Norbury R, Goodwin GM, Harmer CJ (2009). Risk for depression and neural responses to fearful facial expressions of emotion. $\mathrm{Br} J$ Psychiatry 194: 139-145.

Channon S, Baker JE, Robertson MM (1993). Working memory in clinical depression: an experimental study. Psychol Med 23: 87-91. Early evidence for cognitive control deficits in depression.

Chase HW, Camille N, Michael A, Bullmore ET, Robbins TW, Sahakian BJ (2010a). Regret and the negative evaluation of decision outcomes in major depression. Cogn Affect Behav Neurosci 10: 406-413.

Chase HW, Frank MJ, Michael A, Bullmore ET, Sahakian BJ, Robbins TW (2010b). Approach and avoidance learning in patients with major depression and healthy controls: relation to anhedonia. Psychol Med 40: 433-440. A clear demonstration of altered reward learning in anhedonic depressed patients, using a computational modelling approach

Chen CH, Ridler K, Suckling J, Williams S, Fu CH, Merlo-Pich E et al (2007). Brain imaging correlates of depressive symptom severity and predictors of symptom improvement after antidepressant treatment. Biol Psychiatry 62: 407-414.

Chen CH, Suckling J, Ooi C, Fu CH, Williams SC, Walsh ND et al (2008). Functional coupling of the amygdala in depressed patients treated with antidepressant medication. Neuropsychopharmacology 33: 1909-1918

Clark CP, Brown GG, Archibald SL, Fennema-Notestine C, Braun DR, Thomas LS et al (2006). Does amygdalar perfusion correlate with antidepressant response to partial sleep deprivation in major depression? Psychiatry Res 146: 43-51.

Clark L, Chamberlain SR, Sahakian BJ (2009). Neurocognitive mechanisms in depression: implications for treatment. Annu Rev Neurosci 32: 57-74. Clear explanation of the importance of negative affective biases and impaired cognitive control in depression

Clarke H, Flint J, Attwood AS, Munafo MR (2010). Association of the 5- HTTLPR genotype and unipolar depression: a meta-analysis. Psychol Med 40: 1767-1778.

Collins P, Patel V, Josetl S, March D, Insel TR, Daar AS (2011). Grand challenges in global mental health. Nature 475: 27-30.

Costafreda SG, Khanna A, Mourao-Miranda J, Fu CH (2009). Neural correlates of sad faces predict clinical remission to cognitive behavioural therapy in depression. Neuroreport 20: 637-641.

Cremers HR, Demenescu LR, Aleman A, Renken R, van Tol MJ, van der Wee NJ et al (2010). Neuroticism modulates amygdala-prefrontal connectivity in response to negative emotional facial expressions. Neuroimage 49: 963-970.

Dannlowski U, Ohrmann P, Bauer J, Deckert J, Hohoff C, Kugel H et al (2008). 5HTTLPR biases amygdala activity in response to masked facial expressions in major depression. Neuropsychopharmacology 33: 418-424.

Davidson RJ, Irwin W, Anderle MJ, Kalin NH (2003). The neural substrates of affective processing in depressed patients treated with venlafaxine. Am J Psychiatry 160: 64-75. First demonstration that pre-treatment neural response to negative stimuli predicts subsequent recovery.

Davis RN, Massman PJ, Doody RS (2001). Cognitive intervention in Alzheimer disease: a randomized placebo-controlled study. Alzheimer Dis Assoc Disord 15: $1-9$.

DeBattista C, Lembke A, Solvason HB, Ghebremichael R, Poirier J (2004). A prospective trial of modafinil as an adjunctive treatment of major depression. $J$ Clin Psychopharmacol 24: 87-90.

DeRubeis RJ, Siegle GJ, Hollon SD (2008). Cognitive therapy versus medication for depression: treatment outcomes and neural mechanisms. Nat Rev NeurosCi 9: 788-796. Excellent review article highlighting the possibility that differential response to psychological versus pharmacological therapy may be predicted on the basis of pre-treatment neural response to negative stimuli.

Desseilles M, Balteau E, Sterpenich V, Dang-Vu T, Darsaud A, Vandewalle G et al (2009). Abnormal neural filtering of irrelevant visual information in depression. J Neurosci 29: 1395-1403.

Dichter GS, Felder JN, Petty C, Bizzell J, Ernst M, Smoski MJ (2009a). The effects of psychotherapy on neural responses to rewards in major depression. Biol Psychiatry 66: 886-897.

Dichter GS, Felder JN, Smoski MJ (2009b). Affective context interferes with cognitive control in unipolar depression: an $\mathrm{AMRI}$ investigation. J Affect Disord 114: 131-142

Dichter GS, Felder JN, Smoski MJ (2010). The effects of brief behavioral activation therapy for depression on cognitive control in affective contexts: an fMRI investigation. J Affect Disord 126: 236-244.

Dimidjian S, Barrera Jr M, Martell C, Munoz RF, Lewinsohn PM (2011). The origins and current status of behavioral activation treatments for depression. Annu Rev Clin Psychol 7: 1-38. Clear explanation of behavioural activation therapy for depression.

Dimidjian S, Hollon SD, Dobson KS, Schmaling KB, Kohlenberg RJ, Addis ME et al (2006). Randomized trial of behavioral activation, cognitive therapy, and antidepressant medication in the acute treatment of adults with major depression. J Consult Clin Psychol 74: 658-670.

Direnfeld DM, Roberts JE (2006). Mood congruent memory in dysphoria: the roles of state affect and cognitive style. Behav Res Ther 44: 1275-1285.

Dunbar GC, Lishman WA (1984). Depression, recognition-memory and hedonic tone a signal detection analysis. Br J Psychiatry 144: 376-382.

Elliott R, Sahakian BJ, Charmey D (2010). The neural basis of resilience. In: Cooper GL, Field J, Goswami U, Jenkins R and Sahakian BJ (eds). Mental Capital and Wellbeing. Wiley-Blackwell: London.

Elliott R, Rubinsztein JS, Sahakian BJ, Dolan RJ (2002). The neural basis of mood-congruent processing biases in depression. Arch Gen Psychiatry 59: 597604. Early neuroimaging study demonstrating the importance of the anterior cingulate cortex in modulating negative affective biases in depression.

Elliott R, Sahakian BJ, Herrod JJ, Robbins TW, Paykel ES (1997). Abnormal response to negative feedback in unipolar depression: evidence for a diagnosis specific impairment. J Neurol Neurosurg Psychiatry 63: 74-82.

Elliott R, Sahakian BJ, McKay AP, Herrod JJ, Robbins TW, Paykel ES (1996). Neuropsychological impairments in unipolar depression: the influence of perceived failure on subsequent performance. Psychol Med 26: 975-989. First study to propose the idea that hyper-sensitivity to negative feedback may effect other cognitive deficits in depression.

Ellwart T, Rinck M, Becker ES (2003). Selective memory and memory deficits in depressed inpatients. Depress Anxiety 17: 197-206.

Erickson K, Drevets WC, Clark L, Cannon DM, Bain EE, Zarate Jr CA et al (2005). Mood-congruent bias in affective go/no-go performance of unmedicated patients with major depressive disorder. Am J Psychiatry 162: 2171-2173.

Eshel N, Roiser JP (2010). Reward and punishment processing in depression. Biol Psychiatry 68: 118-124. Comprehensive account of abnormal reinforcement processing in depression

Etkin A, Schatzberg AF (2011). Common abnormalities and disorder-specific compensation during implicit regulation of emotional processing in generalized anxiety and major depressive disorders. Am J Psychiatry 168: 968-978.

Fales CL, Barch DM, Rundle MM, Mintun MA, Snyder AZ, Cohen JD et al (2008). Altered emotional interference processing in affective and cognitive-control brain circuitry in major depression. Biol Psychiatry 63: 377-384.

Farb NA, Anderson AK, Bloch RT, Segal ZV (2011). Mood-linked responses in medial prefrontal cortex predict relapse in patients with recurrent unipolar depression. Biol Psychiatry 70: 366-372.

Fava M, Thase ME, DeBattista C (2005). A multicenter, placebo-controlled study of modafinil augmentation in partial responders to selective serotonin reuptake inhibitors with persistent fatigue and sleepiness. J Clin Psychiatry 66: 85-93.

Flory JD, Manuck SB, Matthews KA, Muldoon MF (2004). Serotonergic function in the central nervous system is associated with daily ratings of positive mood. Psychiatry Res 129: 11-19.

Forbes EE, Hariri AR, Martin SL, Silk JS, Moyles DL, Fisher PM et al (2009). Altered striatal activation predicting real-world positive affect in adolescent major depressive disorder. Am J Psychiatry 166: 64-73. Demonstration of a relationship between laboratory-based measurement of reward responsiveness and real-life positive experience.

Forbes EE, Olino TM, Ryan ND, Birmaher B, Axelson D, Moyles DL et al (2010). Reward-related brain function as a predictor of treatment response in adolescents with major depressive disorder. Cogn Affect Behav Neurosci 10: $107-118$ 
Forbes EE, Shaw DS, Dahl RE (2007). Alterations in reward-related decision making in boys with recent and future depression. Biol Psychiatry 61: 633-639.

Foti D, Hajcak G (2011). State sadness reduces neural sensitivity to nonrewards versus rewards. Neuroreport 21: 143-147.

Fournier JC, DeRubeis RJ, Hollon SD, Dimidjian S, Amsterdam JD, Shelton RC et al (2010). Antidepressant drug effects and depression severity: a patient-level meta-analysis. JAMA 303: 47-53.

Fox E, Cahill S, Zougkou K (2010). Preconscious processing biases predict emotional reactivity to stress. Biol Psychiatry 67: 371-377.

Fox E, Ridgewell A, Ashwin C (2009). Looking on the bright side: biased attention and the human serotonin transporter gene. Proc Biol Sci 276: 1747-1751. Clear demonstration of negative affective bias in carriers of the serotonin transporter polymorphism s allele.

Frank E, Cassano GB, Rucci P, Thompson WK, Kraemer HC, Fagiolini A et al (2011). Predictors and moderators of time to remission of major depression with interpersonal psychotherapy and SSRI pharmacotherapy. Psychol Med 41: 151-162.

Fregni F, Marcolin MA, Myczkowski M, Amiaz R, Hasey G, Rumi DO et al (2006). Predictors of antidepressant response in clinical trials of transcranial magnetic stimulation. Int J Neuropsychopharmacol 9: 641-654.

Fritzsche A, Dahme B, Gotlib IH, Joormann J, Magnussen H, Watz H et al (2010). Specificity of cognitive biases in patients with current depression and remitted depression and in patients with asthma. Psychol Med 40: 815-826.

Fruhholz S, Prinz M, Herrmann M (2010). Affect-related personality traits and contextual interference processing during perception of facial affect. Neurosci Lett 469: 260-264.

$\mathrm{Fu}$ CH, Williams SC, Brammer MJ, Suckling J, Kim J, Cleare AJ et al (2007). Neural responses to happy facial expressions in major depression following antidepressant treatment. Am J Psychiatry 164: 599-607.

$\mathrm{Fu}$ CH, Williams SC, Cleare AJ, Brammer MJ, Walsh ND, Kim J et al (2004). Attenuation of the neural response to sad faces in major depression by antidepressant treatment: a prospective, event-related functional magnetic resonance imaging study. Arch Gen Psychiatry 61: 877-889.

$\mathrm{Fu}$ CH, Williams SC, Cleare AJ, Scott J, Mitterschiffthaler MT, Walsh ND et al (2008). Neural responses to sad facial expressions in major depression following cognitive behavioral therapy. Biol Psychiatry 64: 505-512.

Furey ML, Drevets WC (2006). Antidepressant efficacy of the antimuscarinic drug scopolamine: a randomized, placebo-controlled clinical trial. Arch Gen Psychiatry 63: 1121-1129.

Garber J, Clarke GN, Weersing VR, Beardslee WR, Brent DA, Gladstone TR et al (2009). Prevention of depression in at-risk adolescents: a randomized controlled trial. JAMA 301: 2215-2224. Early intervention study demonstrating a reduction in the incidence of depressive episodes following cognitive behavioural therapy in at-risk adolescents.

Gemar MC, Segal ZV, Mayberg HS, Goldapple K, Carney C (2007). Changes in regional cerebral blood flow following mood challenge in drug-free, remitted patients with unipolar depression. Depress Anxiety 24: 597-601.

Gibb BE, Benas JS, Grassia M, McGeary J (2009). Children's attentional biases and 5-HTTLPR genotype: potential mechanisms linking mother and child depression. $J$ Clin Child Adolesc Psychol 38: 415-426.

Gilboa-Schechtman E, Erhard-Weiss D, Jeczemien P (2002). Interpersonal deficits meet cognitive biases: memory for facial expressions in depressed and anxious men and women. Psychiatry Res 113: 279-293.

Gillin JC, Buchsbaum M, Wu J, Clark C, Bunney Jr W (2001). Sleep deprivation as a model experimental antidepressant treatment: findings from functional brain imaging. Depress Anxiety 14: 37-49.

Gotlib $\mathbb{H}$, Cane DB (1987). Construct accessibility and clinical depression: a longitudinal investigation. J Abnorm Psychol 96: 199-204. Early evidence for negative affective biases in depression.

Gotlib IH, Hamilton JP, Cooney RE, Singh MK, Henry ML, Joormann J (2010). Neural processing of reward and loss in girls at risk for major depression. Arch Gen Psychiatry 67: 380-387.

Gotlib $I H$, Jonides J, Buschkuehl M, Joormann J (in press) Memory for affectively valenced and neutral stimuli in depression: evidence from a novel matching task. Cogn Emot.

Gotlib IH, Joormann J (2010). Cognition and depression: current status and future directions. Annu Rev Clin Psychol 6: 285-312. Comprehensive review of cognitive biases in the depressed state.

Gotlib $1 \mathrm{H}$, Kasch KL, Traill S, Joormann J, Arnow BA, Johnson SL (2004a). Coherence and specificity of information-processing biases in depression and social phobia. J Abnorm Psychol 113: 386-398.

Gotlib $I H$, Krasnoperova E, Yue DN, Joormann J (2004b). Attentional biases for negative interpersonal stimuli in clinical depression. J Abnorm Psychol 113: $121-135$.
Gotlib $\Vdash$, McCann CD (1984). Construct accessibility and depression: an examination of cognitive and affective factors. J Pers Soc Psychol 47: 427-439.

Gotlib IH, Sivers H, Gabrieli JD, Whitfield-Gabrieli S, Goldin P, Minor KL et al (2005). Subgenual anterior cingulate activation to valenced emotional stimuli in major depression. Neuroreport 16: 1731-1734.

Gradin VB, Kumar P, Waiter G, Ahearn T, Stickle C, Milders M et al (2011). Expected value and prediction error abnormalities in depression and schizophrenia. Brain 134(Pt 6): 1751-1764.

Grillon C, Levenson J, Pine DS (2007). A single dose of the selective serotonin reuptake inhibitor citalopram exacerbates anxiety in humans: a fear-potentiated startle study. Neuropsychopharmacology 32: 225-231.

Gudayol-Ferre E, Herrera-Guzman I, Camarena B, Cortes-Penagos C, HerreraAbarca JE, Martinez-Medina P et al (2010). The role of clinical variables, neuropsychological performance and SLC6A4 and COMT gene polymorphisms on the prediction of early response to fluoxetine in major depressive disorder. $J$ Affect Disord 127: 343-351.

Gujar N, Yoo SS, Hu P, Walker MP (2011). Sleep deprivation amplifies reactivity of brain reward networks, biasing the appraisal of positive emotional experiences. J Neurosci 31: 4466-4474.

Gur RC, Erwin RJ, Gur RE, Zwil AS, Heimberg C, Kraemer HC (1992). Facial emotion discrimination: II. Behavioral findings in depression. Psychiatry Res 42: 241-251.

Haas BW, Constable RT, Canli T (2008). Stop the sadness: neuroticism is associated with sustained medial prefrontal cortex response to emotional facial expressions. Neuroimage 42: 385-392.

Haas BW, Omura K, Constable RT, Canli T (2007). Emotional conflict and neuroticism: personality-dependent activation in the amygdala and subgenual anterior cingulate. Behav Neurosci 121: 249-256.

Hallion LS, Ruscio AM (in press) A meta-analysis of the effect of cognitive bias modification on anxiety and depression. Psychol Bull.

Hamilton JP, Gotlib IH (2008). Neural substrates of increased memory sensitivity for negative stimuli in major depression. Biol Psychiatry 63: 1155-1162.

Hamilton KE, Dobson KS (2002). Cognitive therapy of depression: pretreatment patient predictors of outcome. Clin Psychol Rev 22: 875-893.

Hariri AR, Mattay VS, Tessitore A, Kolachana B, Fera F, Goldman D et al (2002). Serotonin transporter genetic variation and the response of the human amygdala. Science 297: 400-403.

Harmer CJ (2008). Serotonin and emotional processing: does it help explain antidepressant drug action? Neuropharmacology 55: 1023-1028.

Harmer CJ, Bhagwagar Z, Perrett DI, Vollm BA, Cowen PJ, Goodwin GM (2003a). Acute SSRI administration affects the processing of social cues in healthy volunteers. Neuropsychopharmacology 28: 148-152.

Harmer CJ, Cowen PJ, Goodwin GM (in press) Efficacy markers in depression. J Psychopharmacol.

Harmer CJ, Goodwin GM, Cowen PJ (2009a). Why do antidepressants take so long to work? A cognitive neuropsychological model of antidepressant drug action. $\mathrm{Br}$ J Psychiatry 195: 102-108. Proposal of the cognitive neuropsychological model of antidepressant drug action.

Harmer CJ, Hill SA, Taylor MJ, Cowen PJ, Goodwin GM (2003b). Toward a neuropsychological theory of antidepressant drug action: increase in positive emotional bias after potentiation of norepinephrine activity. Am J Psychiatry 160: 990-992.

Harmer CJ, Mackay CE, Reid CB, Cowen PJ, Goodwin GM (2006). Antidepressant drug treatment modifies the neural processing of nonconscious threat cues. Biol Psychiatry 59: 816-820.

Harmer CJ, O'Sullivan U, Favaron E, Massey-Chase R, Ayres R, Reinecke A et al (2009b). Effect of acute antidepressant administration on negative affective bias in depressed patients. Am J Psychiatry 166: 1178-1184. Demonstration of a reversal of negative bias in depressed patients following acute antidepressant administration.

Harmer CJ, Shelley NC, Cowen PJ, Goodwin GM (2004). Increased positive versus negative affective perception and memory in healthy volunteers following selective serotonin and norepinephrine reuptake inhibition. Am J Psychiatry 161: 1256-1263.

Hayden EP, Dougherty LR, Maloney B, Olino TM, Sheikh H, Durbin CE et al (2008). Early-emerging cognitive vulnerability to depression and the serotonin transporter promoter region polymorphism. J Affect Disord 107: 227-230.

Hecht H, Genzwurker S, Helle M, van Calker D (2005). Social functioning and personality of subjects at familial risk for affective disorder. J Affect Disord 84: 33-42.

Henriques JB, Davidson RJ (2000). Decreased responsiveness to reward in depression. Cogn Emot 14: 711-724. Early demonstration of impaired reward processing in depression.

Hollon SD, Stewart MO, Strunk D (2006). Enduring effects for cognitive behavior therapy in the treatment of depression and anxiety. Annu Rev Psychol 57: 285-315. 
Hooker Cl, Verosky SC, Miyakawa A, Knight RT, D’Esposito M (2008). The influence of personality on neural mechanisms of observational fear and reward learning. Neuropsychologia 46: 2709-2724.

Hu XZ, Lipsky RH, Zhu G, Akhtar LA, Taubman J, Greenberg BD et al (2006). Serotonin transporter promoter gain-of-function genotypes are linked to obsessive-compulsive disorder. Am J Hum Genet 78: 815-826.

Huang J, Perlis RH, Lee PH, Rush AJ, Fava M, Sachs GS et al (2010). Crossdisorder genomewide analysis of schizophrenia, bipolar disorder, and depression. Am J Psychiatry 167: 1254-1263.

Ising M, Lucae S, Binder EB, Bettecken T, Uhr M, Ripke S et al (2009). A genomewide association study points to multiple loci that predict antidepressant drug treatment outcome in depression. Arch Gen Psychiatry 66: 966-975.

Jacobson NS, Dobson KS, Truax PA, Addis ME, Koerner K, Gollan JK et al (1996). A component analysis of cognitive-behavioral treatment for depression. J Consult Clin Psychol 64: 295-304.

Johnson SL, Joormann J, Gotlib $\Vdash$ (2007). Does processing of emotional stimuli predict symptomatic improvement and diagnostic recovery from major depression? Emotion 7: 201-206.

Joormann J, Gilbert K, Gotlib $\Vdash$ (2010a). Emotion identification in girls at high risk for depression. J Child Psychol Psychiatry 51: 575-582.

Joormann J, Gotlib IH (2006). Is this happiness I see? Biases in the identification of emotional facial expressions in depression and social phobia. J Abnorm Psychol 115: $705-714$

Joormann J, Gotlib $\Vdash$ (2007). Selective attention to emotional faces following recovery from depression. J Abnorm Psychol 116: 80-85.

Joormann J, Gotlib $H$ (2008). Updating the contents of working memory in depression: interference from irrelevant negative material. J Abnorm Psychol 117: 182-192. Demonstration of the importance of negative affective cognitive control biases in depression.

Joormann J, Gotlib IH (2010). Emotion regulation in depression: relation to cognitive inhibition. Cogn Emot 24: 281-298.

Joormann J, Hertel PT, LeMoult J, Gotlib $\Vdash$ (2009). Training forgetting of negative material in depression. J Abnorm Psychol 118: 34-43.

Joormann J, Nee DE, Berman MG, Jonides J, Gotlib $I H(2010 b)$. Interference resolution in major depression. Cogn Affect Behav Neurosci 10: 21-33.

Joormann J, Talbot L, Gotlib IH (2007). Biased processing of emotional information in girls at risk for depression. J Abnorm Psychol 116: 135-143.

Kalayam B, Alexopoulos GS (1999). Prefrontal dysfunction and treatment response in geriatric depression. Arch Gen Psychiatry 56: 713-718.

Kalin NH, Davidson RJ, Irwin W, Warner G, Orendi JL, Sutton SK et al (1997). Functional magnetic resonance imaging studies of emotional processing in normal and depressed patients: effects of venlafaxine. J Clin Psychiatry 58(Suppl 16): 32-39.

Kampf-Sherf O, Zlotogorski Z, Gilboa A, Speedie L, Lereya J, Rosca P et al (2004). Neuropsychological functioning in major depression and responsiveness to selective serotonin reuptake inhibitors antidepressants. J Affect Disord 82: 453-459.

Kaplan JS, Erickson K, Luckenbaugh DA, Weiland-Fiedler P, Geraci M, Sahakian BJ et al (2006). Differential performance on tasks of affective processing and decision-making in patients with panic disorder and panic disorder with comorbid major depressive disorder. J Affect Disord 95: 165-171.

Kapur S (2003). Psychosis as a state of aberrant salience: a framework linking biology, phenomenology, and pharmacology in schizophrenia. Am J Psychiatry 160: 13-23.

Keedwell P, Drapier D, Surguladze S, Giampietro V, Brammer M, Phillips M (2009). Neural markers of symptomatic improvement during antidepressant therapy in severe depression: subgenual cingulate and visual cortical responses to sad, but not happy, facial stimuli are correlated with changes in symptom score. J Psychopharmacol 23: 775-788.

Keedwell PA, Andrew C, Williams SC, Brammer MJ, Phillips ML (2005). The neural correlates of anhedonia in major depressive disorder. Biol Psychiatry 58: 843-853.

Keedwell PA, Drapier D, Surguladze S, Giampietro V, Brammer M, Phillips M (2010). Subgenual cingulate and visual cortex responses to sad faces predict clinical outcome during antidepressant treatment for depression. J Affect Disord 120: 120-125.

Kegeles LS, Malone KM, Slifstein M, Ellis SP, Xanthopoulos E, Keilp JG et al (2003). Response of cortical metabolic deficits to serotonergic challenge in familial mood disorders. Am J Psychiatry 160: 76-82.

Kendler KS, Gardner CO, Prescott CA (2002). Toward a comprehensive developmental model for major depression in women. Am J Psychiatry 159: 1133-1145.

Kendler KS, Kessler RC, Neale MC, Heath AC, Eaves LJ (1993). The prediction of major depression in women: toward an integrated etiologic model. Am J
Psychiatry 150: 1139-1148. Demonstration of the importance of neuroticism as a risk factor for depression.

Kennedy SH, Konarski JZ, Segal ZV, Lau MA, Bieling PJ, Mclntyre RS et al (2007). Differences in brain glucose metabolism between responders to CBT and venlafaxine in a 16-week randomized controlled trial. Am J Psychiatry 164: 778-788.

Knutson B, Bhanji JP, Cooney RE, Atlas LY, Gotlib IH (2008). Neural responses to monetary incentives in major depression. Biol Psychiatry 63: 686-692.

Konarski JZ, Kennedy SH, Segal ZV, Lau MA, Bieling PJ, Mclntyre RS et al (2009). Predictors of nonresponse to cognitive behavioural therapy or venlafaxine using glucose metabolism in major depressive disorder. J Psychiatry Neurosci 34: 175-180.

Koster EH, Fox E, MacLeod C (2009). Introduction to the special section on cognitive bias modification in emotional disorders. J Abnorm Psychol 118: 1-4.

Kumar P, Waiter G, Ahearn T, Milders M, Reid I, Steele JD (2008). Abnormal temporal difference reward-learning signals in major depression. Brain 131(Pt 8): 2084-2093.

Kwang T, Wells TT, McGeary JE, Swann Jr WB, Beevers CG (2010). Association of the serotonin transporter promoter region polymorphism with biased attention for negative word stimuli. Depress Anxiety 27: 746-751.

Kyte ZA, Goodyer IM, Sahakian BJ (2005). Selected executive skills in adolescents with recent first episode major depression. J Child Psychol Psychiatry 46: 995-1005.

Lawrence NS, Williams AM, Surguladze S, Giampietro V, Brammer MJ, Andrew C et al (2004). Subcortical and ventral prefrontal cortical neural responses to facial expressions distinguish patients with bipolar disorder and major depression. Biol Psychiatry 55: 578-587.

Le Masurier M, Cowen PJ, Harmer CJ (2007). Emotional bias and waking salivary cortisol in relatives of patients with major depression. Psychol Med 37: 403-410.

LeMoult J, Joormann J, Sherdell L, Wright Y, Gotlib IH (2009). Identification of emotional facial expressions following recovery from depression. $J$ Abnorm Psychol 118: 828-833.

Leppanen JM (2006). Emotional information processing in mood disorders: a review of behavioral and neuroimaging findings. Curr Opin Psychiatry 19: 34-39.

Leppanen JM, Milders M, Bell JS, Terriere E, Hietanen JK (2004). Depression biases the recognition of emotionally neutral faces. Psychiatry Res 128: 123-133.

Liotti M, Mayberg HS, Brannan SK, McGinnis S, Jerabek P, Fox PT (2000). Differential limbic - cortical correlates of sadness and anxiety in healthy subjects: implications for affective disorders. Biol Psychiatry 48: 30-42.

Lisiecka D, Meisenzahl E, Scheuerecker J, Schoepf V, Whitty P, Chaney A et al (2011). Neural correlates of treatment outcome in major depression. Int $J$ Neuropsychopharmacol 14: 521-534

Loewenstein DA, Acevedo A, Czaja SJ, Duara R (2004). Cognitive rehabilitation of mildly impaired Alzheimer disease patients on cholinesterase inhibitors. Am J Geriatr Psychiatry 12: 395-402.

Lozano AM, Mayberg HS, Giacobbe P, Hamani C, Craddock RC, Kennedy SH (2008). Subcallosal cingulate gyrus deep brain stimulation for treatment-resistant depression. Biol Psychiatry 64: 461-467. Demonstration of the efficacy of deep brain stimulation in the subgenual anterior cingulate cortex, and associated blood flow changes in the same region following treatment.

MacLeod C, Rutherford E, Campbell L, Ebsworthy G, Holker L (2002). Selective attention and emotional vulnerability: assessing the causal basis of their association through the experimental manipulation of attentional bias. J Abnorm Psychol 111: 107-123.

Mannie ZN, Bristow GC, Harmer CJ, Cowen PJ (2007). Impaired emotional categorisation in young people at increased familial risk of depression. Neuropsychologia 45: 2975-2980.

Mannie ZN, Harmer CJ, Cowen PJ, Norbury R (2010). A functional magnetic resonance imaging study of verbal working memory in young people at increased familial risk of depression. Biol Psychiatry 67: 471-477.

Mannie ZN, Taylor MJ, Harmer CJ, Cowen PJ, Norbury R (2011). Frontolimbic responses to emotional faces in young people at familial risk of depression. J Affect Disord 130: 127-132.

Markus CR, De Raedt R (2011). Differential effects of 5-HTTLPR genotypes on inhibition of negative emotional information following acute stress exposure and tryptophan challenge. Neuropsychopharmacology 36: 819-826.

Martin M, Ward JC, Clark DM (1983). Neuroticism and the recall of positive and negative personality information. Behav Res Ther 21: 495-503.

Mathews A, Ridgeway V, Williamson DA (1996). Evidence for attention to threatening stimuli in depression. Behav Res Ther 34: 695-705.

Matt GE, Vazquez C, Campbell WK (1992). Mood-congruent recall of affectively toned stimuli-a meta- analytic review. Clin Psychol Rev 12: 227-255.

Matthews A, MacLeod C (2002). Induced emotional biases have causal effects on anxiety. Cogn Emot 16: 310-315. 
Mayberg HS, Brannan SK, Mahurin RK, Jerabek PA, Brickman JS, Tekell JL et al (1997). Cingulate function in depression: a potential predictor of treatment response. Neuroreport 8: 1057-1061.

Mayberg HS, Liotti M, Brannan SK, McGinnis S, Mahurin RK, Jerabek PA et al (1999). Reciprocal limbic-cortical function and negative mood: converging PET findings in depression and normal sadness. Am J Psychiatry 156: 675-682.

Mayberg HS, Lozano AM, Voon V, McNeely HE, Seminowicz D, Hamani C et al (2005). Deep brain stimulation for treatment-resistant depression. Neuron 45: $651-660$

McCabe C, Mishor Z, Cowen PJ, Harmer CJ (2010). Diminished neural processing of aversive and rewarding stimuli during selective serotonin reuptake inhibitor treatment. Biol Psychiatry 67: 439-445. A comparison of the effect of citalopram and fluoxetine on neural responses to primary (taste) reinforcement: only citalopram blunted responses to reward.

McCabe SB, Gotlib $\|$ (1995). Selective attention and clinical depression: performance on a deployment-of-attention task. J Abnorm Psychol 104: 241-245.

McNeely HE, Mayberg HS, Lozano AM, Kennedy SH (2008). Neuropsychological impact of $\mathrm{Cg} 25$ deep brain stimulation for treatment-resistant depression: preliminary results over 12 months. J Nerv Ment Dis 196: 405-410.

Mikhailova ES, Vladimirova TV, Iznak AF, Tsusulkovskaya EJ, Sushko NV (1996). Abnormal recognition of facial expression of emotions in depressed patients with major depression disorder and schizotypal personality disorder. Biol Psychiatry 40: 697-705

Miskowiak K, Papadatou-Pastou M, Cowen PJ, Goodwin GM, Norbury R, Harmer CJ (2007). Single dose antidepressant administration modulates the neural processing of self-referent personality trait words. Neuroimage 37: 904-911.

Mitterschiffthaler MT, Kumari V, Malhi GS, Brown RG, Giampietro VP, Brammer MJ et al (2003). Neural response to pleasant stimuli in anhedonia: an fMRI study. Neuroreport 14: 177-182.

Mogg K, Bradley BP, Williams R (1995). Attentional bias in anxiety and depression: the role of awareness. Br J Clin Psychol 34(Pt 1): 17-36.

Mogg K, Bradley BP, Williams R, Mathews A (1993). Subliminal processing of emotional information in anxiety and depression. J Abnorm Psycho/ 102: 304-311.

Monk CS, Klein RG, Telzer EH, Schroth EA, Mannuzza S, Moulton III JL et al (2008). Amygdala and nucleus accumbens activation to emotional facial expressions in children and adolescents at risk for major depression. Am J Psychiatry 165: 90-98.

Munafo MR, Brown SM, Hariri AR (2008). Serotonin transporter (5-HTTLPR) genotype and amygdala activation: a meta-analysis. Biol Psychiatry 63: 852-857.

Murphy FC, Michael A, Robbins TW, Sahakian BJ (2003). Neuropsychological impairment in patients with major depressive disorder: the effects of feedback on task performance. Psychol Med 33: 455-467.

Murphy FC, Sahakian BJ, Rubinsztein JS, Michael A, Rogers RD, Robbins TW et al (1999). Emotional bias and inhibitory control processes in mania and depression. Psychol Med 29: 1307-1321. Demonstration of negative attentional bias in depression.

Murphy FC, Smith KA, Cowen PJ, Robbins TW, Sahakian BJ (2002). The effects of tryptophan depletion on cognitive and affective processing in healthy volunteers. Psychopharmacology (Berl) 163: 42-53.

Murphy SE, Norbury R, O'Sullivan U, Cowen PJ, Harmer CJ (2009). Effect of a single dose of citalopram on amygdala response to emotional faces. $\mathrm{Br} J$ Psychiatry 194: 535-540.

Murthy NV, Selvaraj S, Cowen PJ, Bhagwagar Z, Riedel WJ, Peers P et al (2010). Serotonin transporter polymorphisms (SLC6A4 insertion/deletion and rs25531) do not affect the availability of 5-HTT to [11C] DASB binding in the living human brain. Neuroimage 52: 50-54

National Institute for Clinical Excellence (2009). Depression: The Treatment and Management of Depression in Adults. National Institute for Clinical Excellence: London, England.

Norbury R, Mackay CE, Cowen PJ, Goodwin GM, Harmer CJ (2007). Short-term antidepressant treatment and facial processing. Functional magnetic resonance imaging study. Br J Psychiatry 190: 531-532.

Norbury R, Mackay CE, Cowen PJ, Goodwin GM, Harmer CJ (2008). The effects of reboxetine on emotional processing in healthy volunteers: an $\mathrm{fMRI}$ study. $\mathrm{Mol}$ Psychiatry 13: 1011-1020.

Norbury R, Taylor MJ, Selvaraj S, Murphy SE, Harmer CJ, Cowen PJ (2009). Shortterm antidepressant treatment modulates amygdala response to happy faces. Psychopharmacology (Berl) 206: 197-204.

Ouimette PC, Klein DN, Pepper CM (1996). Personality traits in the first degree relatives of outpatients with depressive disorders. J Affect Disord 39: 43-53.

Paelecke-Habermann Y, Pohl J, Leplow B (2005). Attention and executive functions in remitted major depression patients. J Affect Disord 89: 125-135.

Perez-Edgar K, Bar-Haim Y, McDermott JM, Gorodetsky E, Hodgkinson CA, Goldman D et al (2010). Variations in the serotonin-transporter gene are associated with attention bias patterns to positive and negative emotion faces. Biol Psychol 83: 269-271.

Persad SM, Polivy J (1993). Differences between depressed and nondepressed individuals in the recognition of and response to facial emotional cues. J Abnorm Psychol 102: 358-368.

Pezawas L, Meyer-Lindenberg A, Drabant EM, Verchinski BA, Munoz KE Kolachana BS et al (2005). 5-HTTLPR polymorphism impacts human cingulate-amygdala interactions: a genetic susceptibility mechanism for depression. Nat Neurosci 8: 828-834.

Phillips ML, Drevets WC, Rauch SL, Lane R (2003a). Neurobiology of emotion perception I: the neural basis of normal emotion perception. Biol Psychiatry 54: 504-514.

Phillips ML, Drevets WC, Rauch SL, Lane R (2003b). Neurobiology of emotion perception II: implications for major psychiatric disorders. Biol Psychiatry 54: 515-528.

Pizzagalli DA, Holmes AJ, Dillon DG, Goetz EL, Birk JL, Bogdan R et al (2009). Reduced caudate and nucleus accumbens response to rewards in unmedicated individuals with major depressive disorder. Am J Psychiatry 166: 702-710.

Pizzagalli DA, losifescu D, Hallett LA, Ratner KG, Fava M (2008). Reduced hedonic capacity in major depressive disorder: evidence from a probabilistic reward task. J Psychiatr Res 43: 76-87.

Potter GG, Kittinger JD, Wagner HR, Steffens DC, Krishnan KR (2004). Prefrontal neuropsychological predictors of treatment remission in late-life depression. Neuropsychopharmacology 29: 2266-2271.

Preiss M, Kucerova H, Lukavsky J, Stepankova H, Sos P, Kawaciukova R (2009). Cognitive deficits in the euthymic phase of unipolar depression. Psychiatry Res 169: 235-239.

Price J, Cole V, Goodwin GM (2009). Emotional side-effects of selective serotonin reuptake inhibitors: qualitative study. $\mathrm{Br} J$ Psychiatry 195: 211-217.

Pringle A, Browning M, Cowen PJ, Harmer CJ (2010). A cognitive neuropsychological model of antidepressant drug action. Prog Neuropsychopharmacol Biol Psychiatry 35: 1586-1592.

Purcell SM, Wray NR, Stone JL, Visscher PM, O'Donovan MC, Sullivan PF et al (2009). Common polygenic variation contributes to risk of schizophrenia and bipolar disorder. Nature 460: 748-752.

Ramel W, Goldin PR, Eyler LT, Brown GG, Gotlib IH, McQuaid JR (2007). Amygdala reactivity and mood-congruent memory in individuals at risk for depressive relapse. Biol Psychiatry 61: 231-239.

Rasmussen NA, Schroder P, Olsen LR, Brodsgaard M, Unden M, Bech P (2005). Modafinil augmentation in depressed patients with partial response to antidepressants: a pilot study on self-reported symptoms covered by the Major Depression Inventory (MDI) and the Symptom Checklist (SCL-92). Nord J Psychiatry 59: 173-178.

Riedel WJ, Eikmans K, Heldens A, Schmitt JA (2005). Specific serotonergic reuptake inhibition impairs vigilance performance acutely and after subchronic treatment. J Psychopharmacol 19: 12-20.

Rijsdijk FV, Riese H, Tops M, Snieder H, Brouwer WH, Smid HG et al (2009). Neuroticism, recall bias and attention bias for valenced probes: a twin study. Psychol Med 39: 45-54.

Rinck M, Becker ES (2005). A comparison of attentional biases and memory biases in women with social phobia and major depression. J Abnorm Psychol 114: 62-74.

Risch N, Herrell R, Lehner T, Liang KY, Eaves L, Hoh J et al (2009). Interaction between the serotonin transporter gene (5-HTTLPR), stressful life events, and risk of depression: a meta-analysis. J Am Med Assoc 301: 2462-2471.

Ritchey M, Dolcos F, Eddington KM, Strauman TJ, Cabeza R (2011). Neural correlates of emotional processing in depression: changes with cognitive behavioral therapy and predictors of treatment response. J Psychiatr Res 45: 577-587.

Robinson MD, Moeller SK, Fetterman AK (2010). Neuroticism and responsiveness to error feedback: adaptive self-regulation versus affective reactivity. J Pers 78: 1469-1496.

Robinson OJ, Cools R, Carlisi C, Sahakian BJ, Drevets WC (in press) Ventral striatum response during reward and punishment reversal learning in unmedicated major depressive disorder. Am J Psychiatry.

Robinson OJ, Sahakian BJ (2008). Recurrence in major depressive disorder: a neurocognitive perspective. Psychol Med 38: 315-318. Explanation of cognitive risk factors for relapse in depression.

Rogers RD, Tunbridge EM, Bhagwagar Z, Drevets WC, Sahakian BJ, Carter CS (2003). Tryptophan depletion alters the decision-making of healthy volunteers through altered processing of reward cues. Neuropsychopharmacology 28: 153-162.

Roiser JP, Blackwell AD, Cools R, Clark L, Rubinsztein DC, Robbins TW et al (2006). Serotonin transporter polymorphism mediates vulnerability to loss of incentive motivation following acute tryptophan depletion. Neuropsychopharmacology 31: 2264-2272.

Roiser JP, Cook LJ, Cooper JD, Rubinsztein DC, Sahakian BJ (2005). Association of a functional polymorphism in the serotonin transporter gene with abnormal emotional processing in ecstasy users. Am J Psychiatry 162: 609-612. 
Roiser JP, Levy J, Fromm SJ, Nugent AC, Talagala SL, Hasler G et al (2009). The effects of tryptophan depletion on neural responses to emotional words in remitted depression. Biol Psychiatry 66: 441-450.

Roiser JP, Muller U, Clark L, Sahakian BJ (2007). The effects of acute tryptophan depletion and serotonin transporter polymorphism on emotional processing in memory and attention. Int J Neuropsychopharmacol 10: 449-461.

Rothen S, Vandeleur CL, Lustenberger Y, Jeanpretre N, Ayer E, Fornerod D et al (2009). Personality traits in children of parents with unipolar and bipolar mood disorders. J Affect Disord 113: 133-141.

Rottenberg J, Joormann J, Brozovich F, Gotlib $\Vdash$ (2005). Emotional intensity of idiographic sad memories in depression predicts symptom levels 1 year later. Emotion 5: 238-242.

Rubinow DR, Post RM (1992). Impaired recognition of affect in facial expression in depressed patients. Biol Psychiatry 31: 947-953.

Ruiz-Caballero JA, Bermudez J (1995). Neuroticism, mood, and retrieval of negative personal memories. J Gen Psychol 122: 29-35.

Sahakian BJ, Malloch G, Kennard C (2010). A UK strategy for mental health and wellbeing. Lancet 375: 1854-1855.

Sahakian BJ, Morein-Zamir S (2011). Depression and resilience: insights from cognitive, neuroimaging and psychopharmacological studies. In: Delgado MR, Phelps EA, Robbins TW (eds). Decision Making, Affect, and Learning: Attention and Performance XXIII. OUP: Oxford.

Salvadore G, Cornwell BR, Colon-Rosario V, Coppola R, Grillon C, Zarate Jr CA et al (2009). Increased anterior cingulate cortical activity in response to fearful faces: a neurophysiological biomarker that predicts rapid antidepressant response to ketamine. Biol Psychiatry 65: 289-295.

Salvadore G, Cornwell BR, Sambataro F, Latov D, Colon-Rosario V, Carver F et al (2010). Anterior cingulate desynchronization and functional connectivity with the amygdala during a working memory task predict rapid antidepressant response to ketamine. Neuropsychopharmacology 35: 1415-1422.

Schaefer HS, Putnam KM, Benca RM, Davidson RJ (2006). Event-related functional magnetic resonance imaging measures of neural activity to positive social stimuli in pre- and post-treatment depression. Biol Psychiatry 60: 974-986.

Schildkraut JJ (1965). The catecholamine hypothesis of affective disorders: a review of supporting evidence. Am J Psychiatry 122: 509-522.

Schleim S, Roiser JP (2009). FMRI in translation: the challenges facing real-world applications. Front Hum Neurosci 3: 63.

Schoning S, Zwitserlood P, Engelien A, Behnken A, Kugel H, Schiffbauer $\mathrm{H}$ et al (2009). Working-memory fMRI reveals cingulate hyperactivation in euthymic major depression. Hum Brain Mapp 30: 2746-2756.

Scoriels L, Barnett JH, Murray GK, Cherukuru S, Fielding M, Cheng F et al (2011). Effects of modafinil on emotional processing in first episode psychosis. Biol Psychiatry 69: 457-464.

Segal ZV, Gemar M, Truchon C, Guirguis M, Horowitz LM (1995). A priming methodology for studying self-representation in major depressive disorder. $J$ Abnorm Psychol 104: 205-213.

Serretti A, Kato M, De Ronchi D, Kinoshita T (2007). Meta-analysis of serotonin transporter gene promoter polymorphism (5-HTTLPR) association with selective serotonin reuptake inhibitor efficacy in depressed patients. Mol Psychiatry 12: 247-257.

Sheline YI, Barch DM, Donnelly JM, Ollinger JM, Snyder AZ, Mintun MA (2001). Increased amygdala response to masked emotional faces in depressed subjects resolves with antidepressant treatment: an fMRI study. Biol Psychiatry 50: 651-658. First demonstration that treatment normalises negative affective biases in depression.

Siegle GJ, Carter CS, Thase ME (2006). Use of FMRI to predict recovery from unipolar depression with cognitive behavior therapy. Am J Psychiatry 163: 735-738. First demonstration that pre-treatment neural response to negative stimuli can predict subsequent improvement following cognitive behavioural therapy

Siegle GJ, Steinhauer SR, Friedman ES, Thompson WS, Thase ME (2011). Remission prognosis for cognitive therapy for recurrent depression using the pupil: utility and neural correlates. Biol Psychiatry 69: 726-733.

Siegle GJ, Thompson W, Carter CS, Steinhauer SR, Thase ME (2007). Increased amygdala and decreased dorsolateral prefrontal BOLD responses in unipolar depression: related and independent features. Biol Psychiatry 61: 198-209.

Simon J, Pilling S, Burbeck R, Goldberg D (2006). Treatment options in moderate and severe depression: decision analysis supporting a clinical guideline. $\mathrm{Br} \mathrm{J}$ Psychiatry 189: 494-501.

Sitzer DI, Twamley EW, Jeste DV (2006). Cognitive training in Alzheimer's disease: a meta-analysis of the literature. Acta Psychiatr Scand 114: 75-90.

Smith DJ, Muir WJ, Blackwood DH (2006). Neurocognitive impairment in euthymic young adults with bipolar spectrum disorder and recurrent major depressive disorder. Bipolar Disord 8: 40-46.

Speer AM, Kimbrell TA, Wassermann EM, D Repella J, Willis MW, Herscovitch P et al (2000). Opposite effects of high and low frequency rTMS on regional brain activity in depressed patients. Biol Psychiatry 48: 1133-1141. Demonstration that transcranial magnetic stimulation at clinical efficacious levels alters prefrontal blood flow

Steele JD, Kumar P, Ebmeier KP (2007). Blunted response to feedback information in depressive illness. Brain 130(Pt 9): 2367-2374.

Stein MB, Simmons AN, Feinstein JS, Paulus MP (2007). Increased amygdala and insula activation during emotion processing in anxiety-prone subjects. Am J Psychiatry 164: 318-327.

Surguladze S, Brammer MJ, Keedwell P, Giampietro V, Young AW, Travis MJ et al (2005). A differential pattern of neural response toward sad versus happy facial expressions in major depressive disorder. Biol Psychiatry 57: 201-209.

Surguladze SA, Young AW, Senior C, Brebion G, Travis MJ, Phillips ML (2004). Recognition accuracy and response bias to happy and sad facial expressions in patients with major depression. Neuropsychology 18: 212-218.

Suslow T, Konrad C, Kugel H, Rumstadt D, Zwitserlood P, Schoning S et al (2010). Automatic mood-congruent amygdala responses to masked facial expressions in major depression. Biol Psychiatry 67: 155-160.

Taylor Tavares JV, Clark L, Cannon DM, Erickson K, Drevets WC, Sahakian BJ (2007). Distinct profiles of neurocognitive function in unmedicated unipolar depression and bipolar II depression. Biol Psychiatry 62: 917-924.

Taylor Tavares JV, Clark L, Furey ML, Williams GB, Sahakian BJ, Drevets WC (2008). Neural basis of abnormal response to negative feedback in unmedicated mood disorders. Neuroimage 42: 1118-1126.

Teasdale JD, Segal Z, Williams JM (1995). How does cognitive therapy prevent depressive relapse and why should attentional control (mindfulness) training help? Behav Res Ther 33: 25-39.

Teasdale JD, Segal ZV, Williams JM, Ridgeway VA, Soulsby JM, Lau MA (2000). Prevention of relapse/recurrence in major depression by mindfulness-based cognitive therapy. J Consult Clin Psychol 68: 615-623.

Thomas EJ, Elliott R, McKie S, Arnone D, Downey D, Juhasz G et al (2011). Interaction between a history of depression and rumination on neural response to emotional faces. Psychol Med 41: 1845-1855.

Timbremont B, Braet C (2004). Cognitive vulnerability in remitted depressed children and adolescents. Behav Res Ther 42: 423-437.

Tran TB, Siemer M, Joormann J (2011). Implicit interpretation biases affect emotional vulnerability: a training study. Cogn Emot 25: 546-558.

Tranter R, Bell D, Gutting P, Harmer C, Healy D, Anderson IM (2009). The effect of serotonergic and noradrenergic antidepressants on face emotion processing in depressed patients. J Affect Disord 118: 87-93.

Trivedi MH, Rush AJ, Wisniewski SR, Nierenberg AA, Warden D, Ritz L et al (2006). Evaluation of outcomes with citalopram for depression using measurement-based care in STAR*D: implications for clinical practice. Am J Psychiatry 163: 28-40.

Turner DC, Clark L, Dowson J, Robbins TW, Sahakian BJ (2004a). Modafinil improves cognition and response inhibition in adult attention-deficit/hyperactivity disorder. Biol Psychiatry 55: 1031-1040.

Turner DC, Clark L, Pomarol-Clotet E, McKenna P, Robbins TW, Sahakian BJ (2004b). Modafinil improves cognition and attentional set shifting in patients with chronic schizophrenia. Neuropsychopharmacology 29: 1363-1373.

Turner DC, Robbins TW, Clark L, Aron AR, Dowson J, Sahakian BJ (2003). Cognitive enhancing effects of modafinil in healthy volunteers. Psychopharmacology (Berl) 165: 260-269.

Uher R, Perroud N, Ng MY, Hauser J, Henigsberg N, Maier W et al (2010). Genomewide pharmacogenetics of antidepressant response in the GENDEP project. Am J Psychiatry 167: 555-564.

van der Veen FM, Evers EA, Deutz NE, Schmitt JA (2007). Effects of acute tryptophan depletion on mood and facial emotion perception related brain activation and performance in healthy women with and without a family history of depression. Neuropsychopharmacology 32: 216-224.

van Marle HJ, Tendolkar I, Urner M, Verkes RJ, Fernandez G, van Wingen G (2011). Subchronic duloxetine administration alters the extended amygdala circuitry in healthy individuals. Neuroimage 55: 825-831.

Victor TA, Furey ML, Fromm SJ, Ohman A, Drevets WC (2010). Relationship between amygdala responses to masked faces and mood state and treatment in major depressive disorder. Arch Gen Psychiatry 67: 1128-1138. Comprehensive study of preconscious negative affective biases in depression and their treatment, including a placebo group of depressed patients

Wacker J, Dillon DG, Pizzagalli DA (2009). The role of the nucleus accumbens and rostral anterior cingulate cortex in anhedonia: integration of resting EEG, fMRI, and volumetric techniques. Neuroimage 46: 327-337.

Walsh ND, Williams SC, Brammer MJ, Bullmore ET, Kim J, Suckling J et al (2007). A longitudinal functional magnetic resonance imaging study of verbal working memory in depression after antidepressant therapy. Biol Psychiatry 62: 1236-1243. Demonstration of impaired cognitive control in depression, though with some changes following treatment. 
Wang L, LaBar KS, Smoski M, Rosenthal MZ, Dolcos F, Lynch TR et al (2008). Prefrontal mechanisms for executive control over emotional distraction are altered in major depression. Psychiatry Res 163: 143-155.

Watkins ER, Baeyens CB, Read R (2009). Concreteness training reduces dysphoria: proof-of-principle for repeated cognitive bias modification in depression. J Abnorm Psychol 118: 55-64.

Williams JM, Mathews A, MacLeod C (1996). The emotional Stroop task and psychopathology. Psychol Bull 120: 3-24.
Yoon KL, Joormann J, Gotlib IH (2009). Judging the intensity of facial expressions of emotion: depression-related biases in the processing of positive affect. J Abnorm Psychol 118: 223-228

Zarate Jr CA, Singh JB, Carlson PJ, Brutsche NE, Ameli R, Luckenbaugh DA et al (2006). A randomized trial of an $\mathrm{N}$-methyl-D-aspartate antagonist in treatmentresistant major depression. Arch Gen Psychiatry 63: 856-864. Demonstration that ketamine has a rapid-onset antidepressanteffect. 